\title{
The Response of Glass Window Systems to Blast Loadings: An Overview
}

\author{
Xihong Zhang ${ }^{*}$ and Hong Hao
}

Centre for Infrastructural Monitoring and Protection, School of Civil and Mechanical Engineering, Curtin University

Ken St., Bentley WA 6102, Australia

Email: xihong.zhang@curtin.edu.au

\begin{abstract}
The failure of glass windows in terrorist bombing attacks and accidental explosion incidents has been cited as one of the major causes to the vast casualties. Many studies have been carried out to investigate the response and vulnerability of glass windows against blast loadings. These include laboratory and field tests that have been carried out to experimentally study glass window performance under explosion scenarios; and development of analytical and numerical models to analyze and predict glass window responses. This article reviews literatures on the studies of the response of glass window systems to blast loadings. Over 100 papers and documents that are available in open literature are reviewed. The background and history of the studies on the topic is also briefed. Understandings about the dynamic material properties of glass and available material models are summarized. Popularly used analysis methods and design standards for monolithic and laminated glass windows are outlined, and their accuracies are discussed. Recent studies including analytical solution, numerical simulation and experimental investigations on glass window systems are summarized. Mitigation measures for blast resistant windows are also briefly discussed.
\end{abstract}

Keyword: Glass windows, dynamic material properties, blast

\section{Introduction}

Glass is a popular material that has been widely used for windows and façade in many structures. It is also very brittle and fragile compared to most of other building 
materials such as structural steel and concrete. As such traditional glass windows are very vulnerable to extreme loads such as blast. Post-event investigations of terrorist bombing attacks and accidental explosions have cited the majority of human casualties were mainly by the shattered glass windows [1-3]. For example, the accidental gas explosion in Texas in 1986 fractured glass windows in a radius of 800 meters. Significant number of casualties was due to flying glass shards from fractured windows. More recently, the Jakarta terrorist bombing attack on the Australian Embassy in 2004 (Figure 1a) did not cause any major structural damage but shattered glass windows in buildings within 500 meters. 9 people were killed and over 150 were injured, most of whom were victims inside the buildings and hurt by glass fragments. Similarly in the Norway attack in 2011 (Figure 1b), the blast pressure from the car bomb smashed nearly all the glass windows of the Oslo executive government building. 209 out of the 325 injuries were associated with glass lacerations. To better design of glass windows for protection of people in possible terrorist bombing attack and accidental explosion, a thorough understanding of the behavior of glass windows subjected to blast loading is needed.

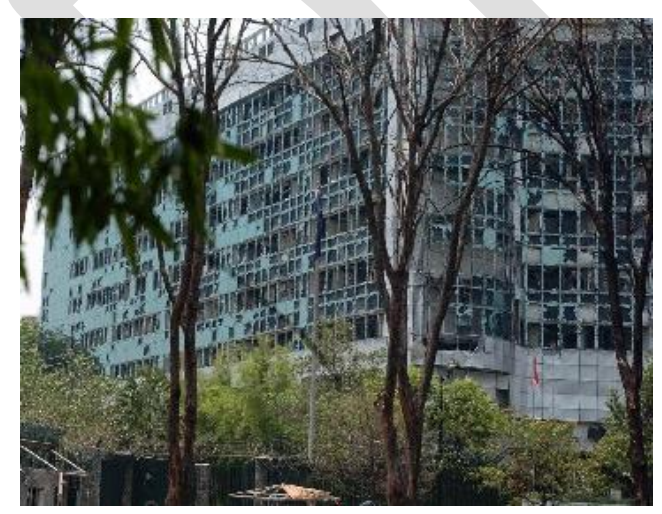

a) Jakarta bombing, 2004

(Courtesy: Xinhua Photo/Ainiwaer)

Figure 1 Window failures in bombing attacks

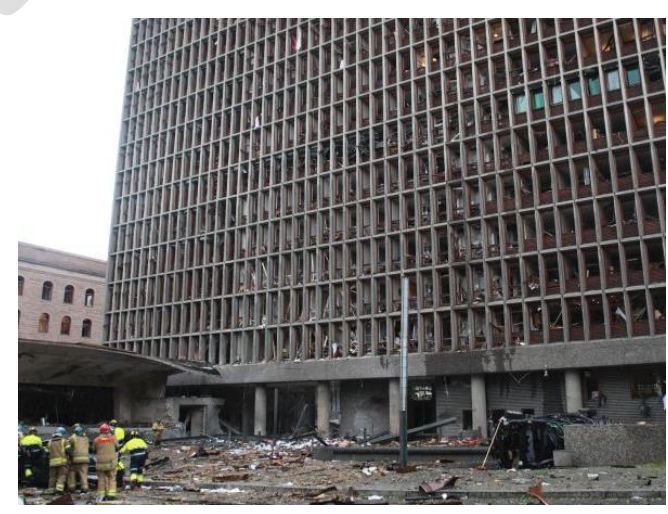

b) Shattered glass windows in Norway attack, 2011 (Courtesy: Heidi Wideroe)

The concept of laminated safety glass was first introduced by French chemist

Edouard Benedictus in 1903 which was later patented in 1909 [4]. Investigations on 
the vulnerability of glass windows subjected to blast loading date back to World War II [5]. A large number of field blast tests were conducted primarily on monolithic glass windows targeting at mitigating fragment hazard during wartime. Minimum charge weight and stand-off distance were obtained for the breakage threshold of monolithic glass pane. Equivalent static and dynamic analysis methods with single degree of freedom (SDOF) simplification were developed to predict glass breakage. With the aid of finite element method the analysis on the response of glass windows was advanced in the 1980's [6, 7]. Substantial research was carried out by the US Navy in this period to investigate the blast resistant capacity of monolithic glass windows against accidental explosions. Field testing data on monolithic glass windows was incorporated with analytical and numerical results. Design codes such as TM 5-1300 [8] (later known as UFC 3-340-02 [9]) and ASTM F2248-09 [10] were drafted to guide analysis and design of monolithic glass windows.

The study of laminated glass response to air blast load has been carried out since it was firstly introduced in automobile industry and then used as protective structural glazing. The concept of laminated glass was first introduced in the 1940s by applying an additional plastic film to the back of a glass pane to improve window performance [11]. The Irish terrorism attacks on British barracks in UK during 1980s and 1990s boosted the investigation on blast loading resistance capacities of laminated glass. Many field blast tests were conducted by the UK government departments to investigate glass window vulnerability to terrorist attacks. Empirical design procedures defining the minimum stand-off distance to prevent window failure as well as fragility curves were drafted [12]. However, only limited window sizes were tested. Due to the non-linear relationship between window response and blast loading it was later realized that interpolating empirical data to windows of other dimensions 
and blast loading scenarios other than tested could lead to enormous errors. Numerical methods and analytical solutions have been intensively used to study the response of laminated glass windows ever since. Nevertheless, it should be noted that due to the lack of dynamic material properties, most previous numerical and analytical models adopted an elastic model for glass and a viscoelastic model for interlayer with their static material properties. Under blast loading, the strain rates that glass and interlayer experience could be more than $100 \mathrm{~s}^{-1}$. Material strength and response at such high strain rates could be very different from those under static loadings. Therefore, this simplification might lead to inaccurate predictions of window responses. Reliable analysis on the response of laminated glass windows with accurate material properties is badly needed.

This paper reviews the up-to-date understandings about the dynamic material properties of construction glass materials. Recent development of dynamic material models for annealed glass is reviewed. The response of monolithic glass windows under blast loading, and the fragment characteristics from shattered glass pane under blast are discussed. Recent experimental investigations on the dynamic material properties of PVB (Polyvinyl butyral) and SGP (SentryGlas ${ }^{\circledR}$ Plus) interlayer materials are summarized. Numerical and experimental investigations on laminated glass window responses to blast loads are discussed. Available mitigation measures for blast resistant window systems are also reviewed.

\section{Glass Material}

\subsection{Material properties}

\subsubsection{Glass categories}

Glass is an amorphous solid material which is often transparent. It is also a complex material. Variation in its chemical compositions results in diversified material 
characteristics. Glass is produced by heating a mixture of raw minerals above a transition point. The molten glass is floated on top of molten tin after which it is slowly cooled to room temperature without being quenched in an annealing lehr [13] (Figure 2). Window glass normally adopts soda-lime glass (with about $72 \%$ mass proportions of silicone dioxide also known as 'silica'), while sodium borosilicate glass with higher ratio of silicone dioxide (approximately $81 \%$ ) has better temperature and shock resistance which is often used for reagent. Other silicate glass include fused quartz, lead oxide glass, aluminosliciate glass, etc. which exhibit unique characteristics respectively but barely used for construction glazing.

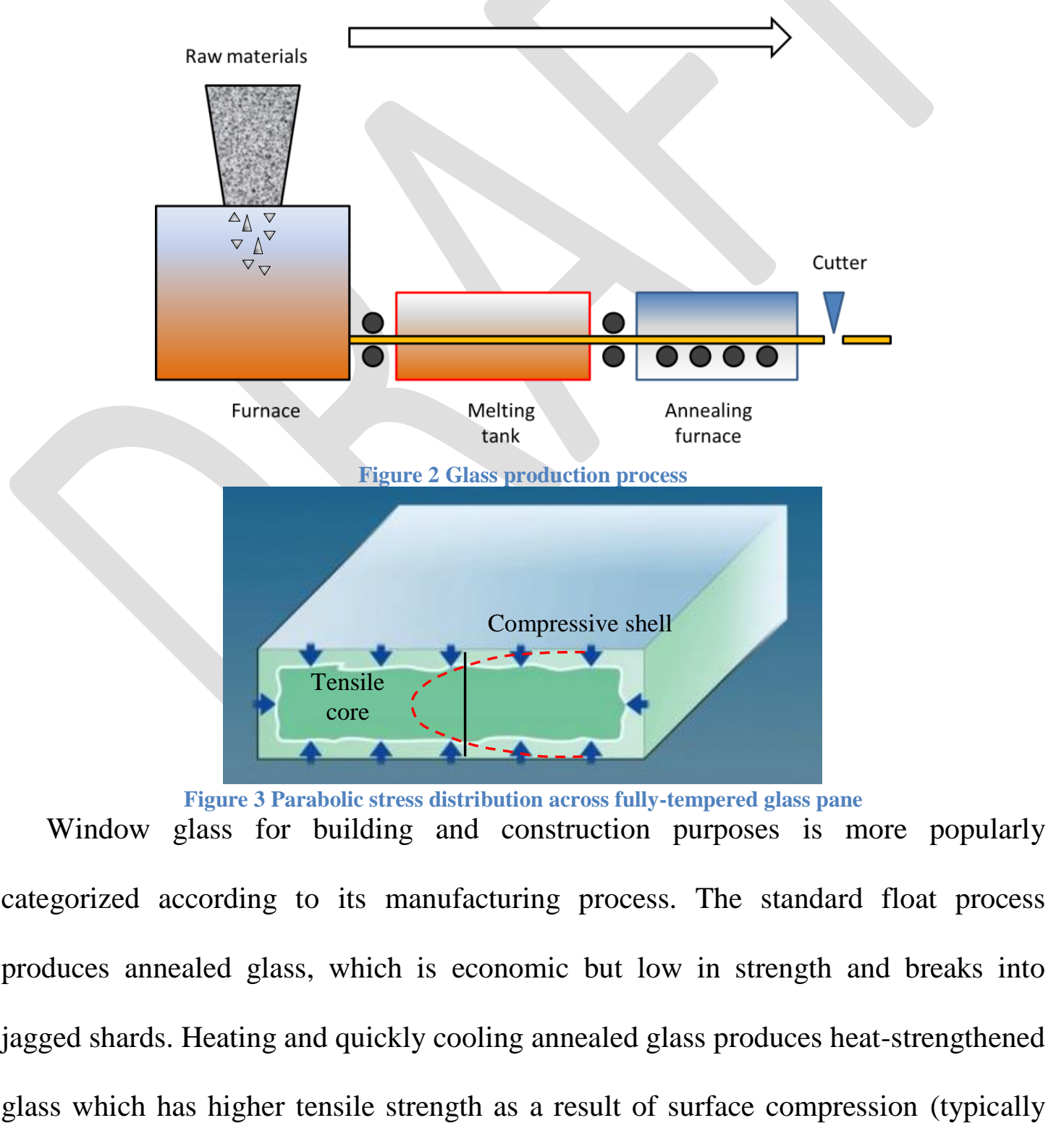


40MPa). Similarly to annealed glass, heat-strengthened glass breaks into large pieces of jagged shards. Heating annealed glass up to about $700^{\circ} \mathrm{C}$, and then immediately cooling it produces fully (thermally) tempered glass. The tempering process introduces compressive stress to pane surface and tensile stress in pane center. The stress distribution across glass pane can be represented by a parabola [14] (Figure 3). Like heat-strengthened glass, typical tempered glass has a surface compression of about 100MPa. The introduced surface compression leads to the flexural strength in tempered glass four to five times higher than that in annealed glass. Because of the stored elastic energy during the tempering process, once a crack reaches the tensile core, continuous cracking can be triggered in tempered glass pane which shatters into numerous small and fine cubicles. Due to this feature tempered glass is entitled as 'safety glass' which is widely installed to mitigate laceration hazards. However, under high-rate dynamic loading the propagation of cracks within tempered glass may not necessarily reaches the surface but stay in the tensile core [15]. In other words, only the central layer of the tempered glass would break into small cubicles, and the entire pane would remain intact until it further ruptures into large pieces. Field blast tests on monolithic tempered glass observed that tempered glass could also break into large pieces of fragments with sharp edges [16, 17], which could also impose significant threats to people in the surrounding area. The fragment hazards mitigation effect of tempered glass is therefore not necessarily always achievable when subjected to blast load. Proper assessment of the tempered glass fragment threats is therefore also needed. Considering the described manufacturing process, the stress distributions in heat strengthened and tempered glass are not necessarily uniform. Studies on glass mechanical properties are therefore usually performed on annealed glass only.

\subsubsection{Glass static properties}


The behavior of annealed glass under static loading is brittle and linear elastic till fracture. The theoretical tensile strength of glass material can be up to $21 \mathrm{GPa}$ [18]. Nevertheless, architectural annealed glass normally fails at around a stress level of $100 \mathrm{MPa}$ or even lower due to the existence of surface flaws which are also known as Griffith flaw [19]. Griffith presumed that glass fractures initiate at these flaws [19]. A normal distribution [20] or a Weibull distribution with single or two parameters is normally used to represent the uncertainties in glass strength [21, 22]. The measured static strengths of annealed glass vary significantly. The European glazing standard prEN 13474-3 [23] reports the measured glass fracture strengths from over 700 ringon-ring tests varying from $30 \mathrm{MPa}$ to $120 \mathrm{MPa}$. The split tensile strength tested on $15 \mathrm{~mm} \times 15 \mathrm{~mm}$ (diameter $\mathrm{x}$ length) annealed glass cylinder was only about $20 \mathrm{MPa}$ [24]. The significant variation is not only because of the different types of tensile strengths measured, i.e., bi-flexural, split-tensile, etc. but is mainly attributed to the surface conditions of the different tested glass panes. The strength of a glass pane heavily depends on the position and direction of flaws on its surface. A reduction in both the mean strength and standard deviation will be found with an increased number of flaws due to weathering or abrasion to the tested glass pane [25].

\subsubsection{Glass dynamic properties}

Glass behaves differently under dynamic loading. The fracture process and densification behavior of soda-lime (annealed) glass under shock loading were intensively investigated through plate impact test [26-28]. The influence of surface flaws becomes less prominent at high strain rates especially for glass under compression. This is because under shock loading there is not sufficient time for glass to crack at the pre-existing flaws. Instead bulk damage would be triggered by high intensity stress as shown in Figure 4. Loading rate has also been found to have a 
significant influence on glass strength. This is because the roots of surface flaws on glass are subjected to stress corrosion from moisture and the pre-existing cracks take time to develop. Analytical study using Brown's equation [29] shows that glass strength could increase as much as three times under dynamic loading. Some laboratory tests were reported to experimentally prove the dynamic increase effect on glass material strength [30, 31]. More systematic studies were recently carried out using Split-Hopkinson Pressure Bar to quantify the strain rate effect on architectural annealed glass [24]. The dynamic increase factors (DIF) for both compressive and split-tensile strengths at various strain rates were obtained from laboratory testing data [24]. Bi-linear relations between glass compressive and tensile DIFs and strain rates were derived (Figure 5). Some design codes recommend including the strain rate effect of glass material in the design analysis. For instance, British code [32] suggests a characteristic strength of $80 \mathrm{MPa}$ for glass window design against blast loading, while that for quasi-static loading is $45 \mathrm{MPa}$, implying a dynamic strength increment of about 1.78 times. It is worth noting that despite the recent studies mentioned above [24], the dynamic increase effect on annealed glass used in building constructions is in general under investigated. Considering the large variations found on glass static strength, more dynamic tests are needed to better describe the glass dynamic material properties.
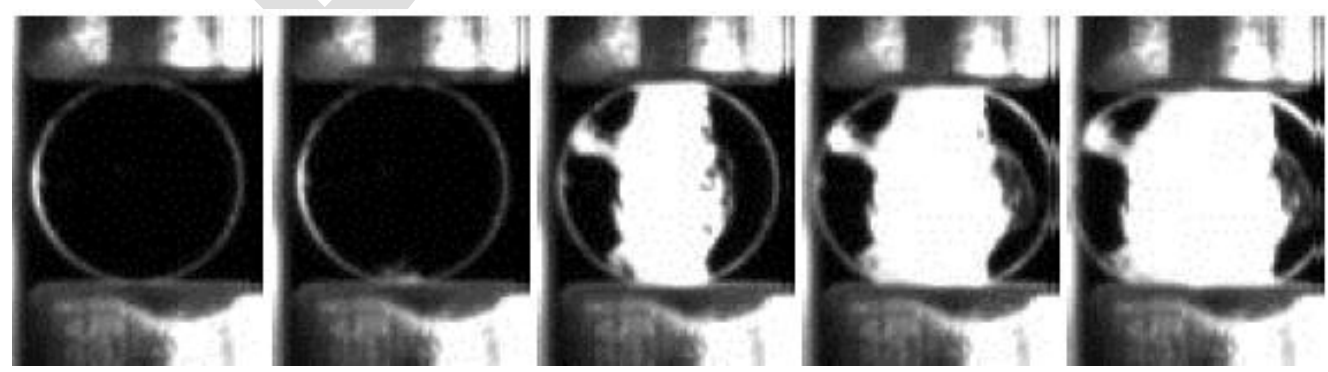

a) High-speed camera images of glass cylinders under dynamic split-tension [31] 

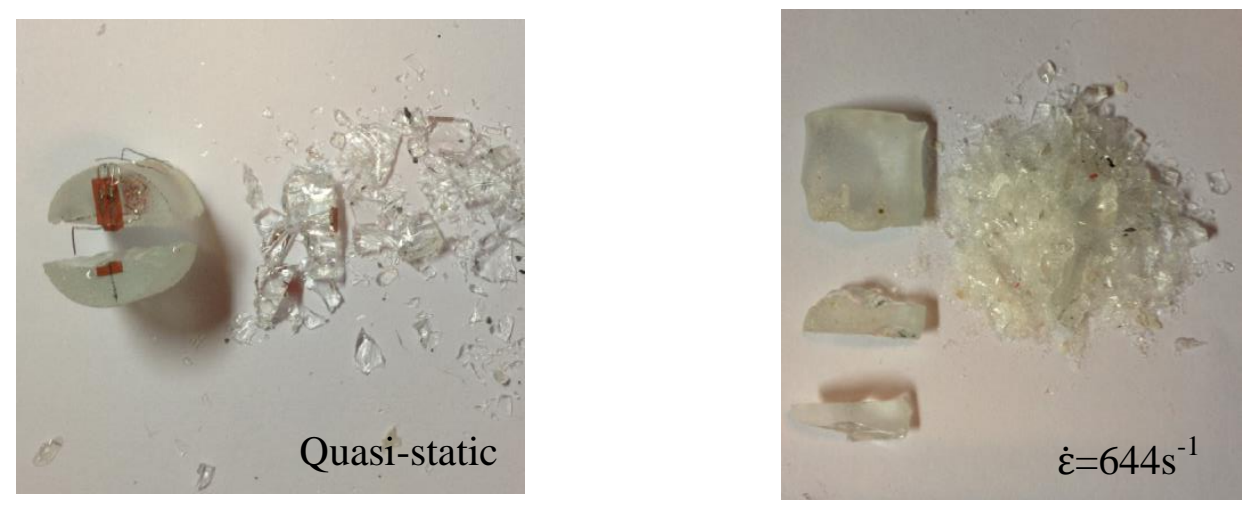

b) Failure states of glass specimens [24]
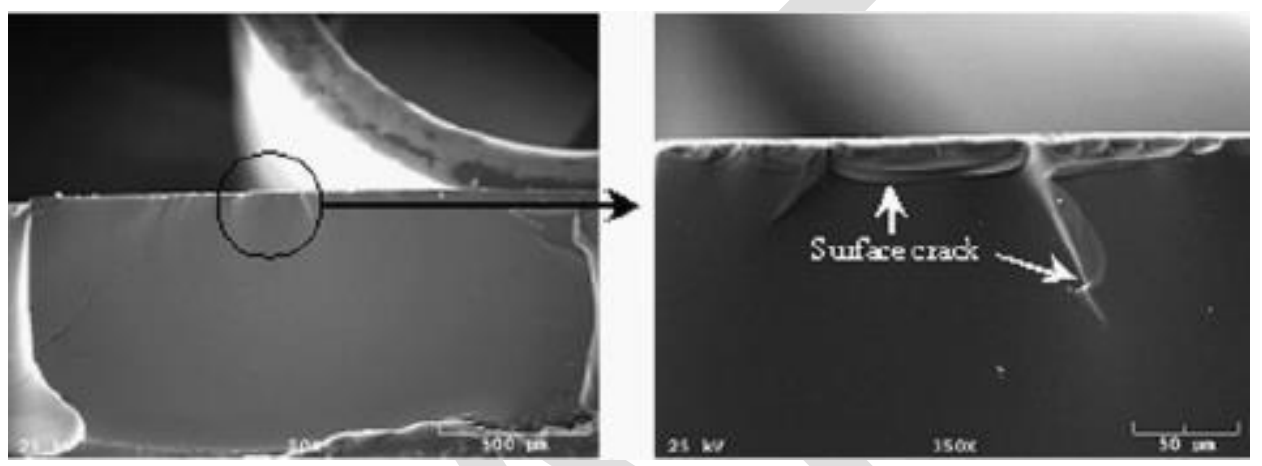

c) Scanning electron microscopic images of failed specimen [33]

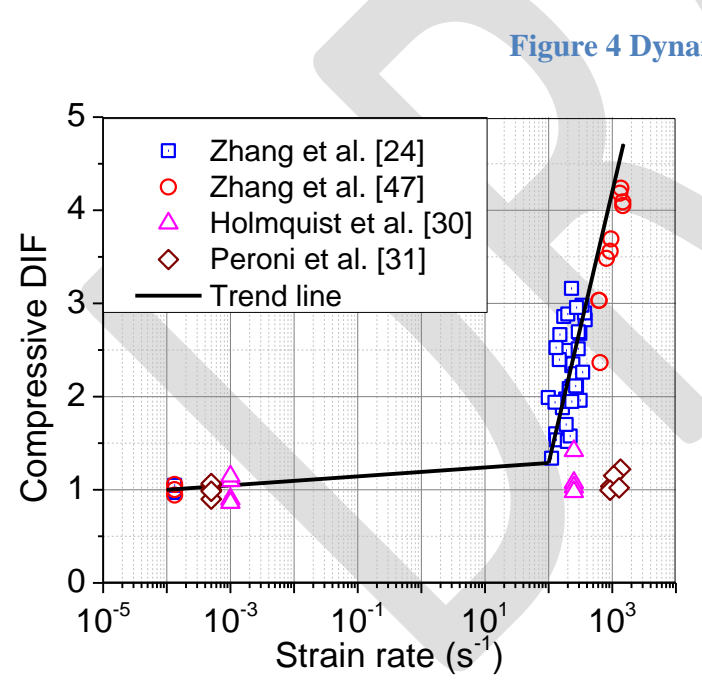

a) Compressive DIF vs. strain rates

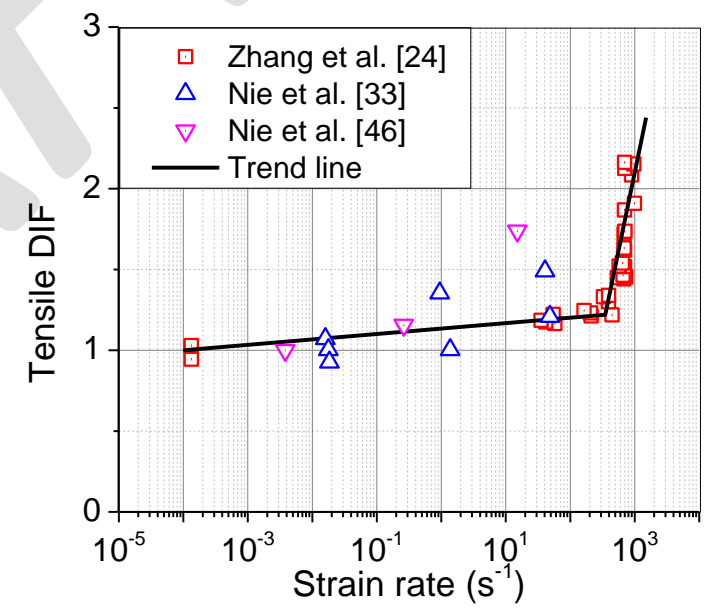

b) Tensile DIF vs. strain rates

Figure 5 Glass compressive and tensile dynamic increment factors vs. strain rates [24]

\subsection{Glass material models}

To predict glass pane response with analytical and/or numerical approaches, several glass material models are available. Glass failure prediction model (GFPM) by 
Beason and his co-workers [21] is one of the most widely adopted models when designing glass windows under quasi-static loading. This is a statistical model based on the assumption that surface flaws (size and orientation) determine the glass cracking strength. The parameters of the Weibull model are determined from best fitting the testing data on glass panels. Many standards employ GFPM in their designs of glass window systems [34]. However, the generality and validity of the parameters in GFPM have often been questioned. Some modifications and improved model have been proposed by different researchers $[35,36]$. On the other hand, many European standards such as prEN 13474-1 [37] adopt a deterministic model which precedes the statistical method (GFPM). The failure of glass pane is based on the allowable tensile strength of glass. The influence of surface condition and loading duration are also considered.

With the overwhelming usage of glass failure prediction model in analyzing glass window behavior under quasi-static loading as well as the understanding that under such loading glass behaves basically linear elastic till failure, also because of a lack of glass dynamic material model, in analyzing glass window dynamic response, a linear elastic model with static material properties had been often adopted in modelling glass material for many years [38-41]. With more recent understandings and testing results available on glass dynamic material properties, some dynamic material models for glass have been developed and utilized. In general, these models can be categorized into three levels, micro-level model [42], explicit crack development model [43] and marco-level model $[44,45]$. The micro-level model is beneficial in investigating shock wave propagation in glass and equation of state (EOS). The explicit crack development model shows competency in predicting crack initiation and extension. 
However, considering computational efficiency, these two approaches become less suitable for studying full-scale glass window response.

The macro-level models are generally continuum models. Grujicic et al. [44] formulated a continuum model based on flaw distribution on pane surface in analyzing glass pane response under ballistic impact (Figure 6a). The concept of shielding zone was introduced as glass damage propagates through the thick glass armor. Johnson-Holmquist Ceramic (JH2) model [45] is another popularly used macro-level model which considers glass strain-rate effect, material damage and also confinement effect. Material constants for float glass [30] were determined in early 1990s through laboratory tests on limited number of glass specimens, which may not necessarily reveal glass dynamic material properties. Moreover, the original material constants were found not suitable for modelling architectural annealed glass as the compressive and tensile strengths tested on float glass were over $1 \mathrm{GPa}$ and 100MPa, respectively [30]. Both the compressive and tensile strengths are much higher than those experimental results on architectural annealed glass [24]. The discrepancy is believed to be attributed to differences in sample surface conditions. As pointed out by Nie et al. [33, 46] glass strength exceeding $1 \mathrm{GPa}$ were normally produced by submersing the specimen in acid fluid or going through fine polish to blunt out surface cracks. This could be suitable for transparent armor for military purpose but is not a process in producing construction glass panels. Modifications to material constants of $\mathrm{JH} 2$ model were recently conducted since more testing data on annealed glass dynamic material properties become available (strength and EOS) [24, 27, 4749]. The strength model, dynamic increase factor and also EOS were modified (Figure 6b) [47]. Intensive verifications proved the accuracy of modified material constants for $\mathrm{JH} 2$ and they are capable of properly predicting the response of glass window 
under shock and impact loads [47]. It should be pointed out that JH2 model was initially developed to simulate glass ballistic performance; the tensile region in the strength model was not properly described. Moreover, there is still a lack of testing data on the hydro-tension of glass material. Further refinement on construction glass material properties that can be used in $\mathrm{JH} 2$ model is therefore still needed.

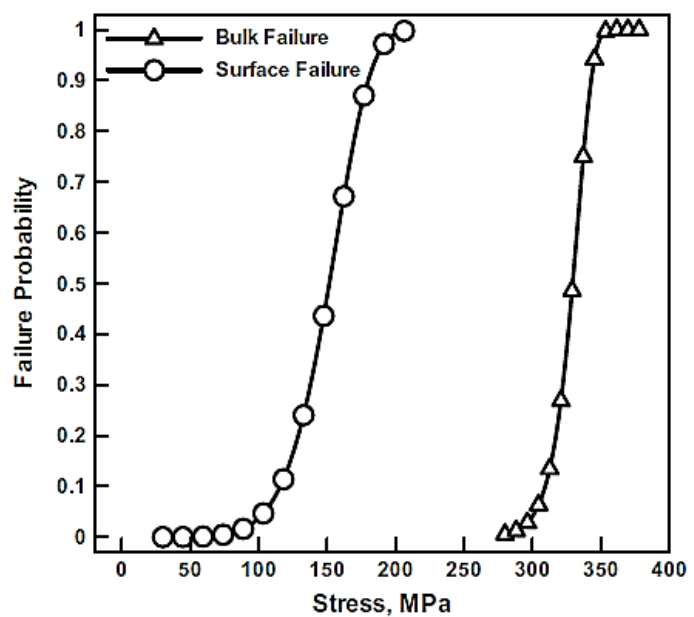

a) Cumulative glass failure [44]

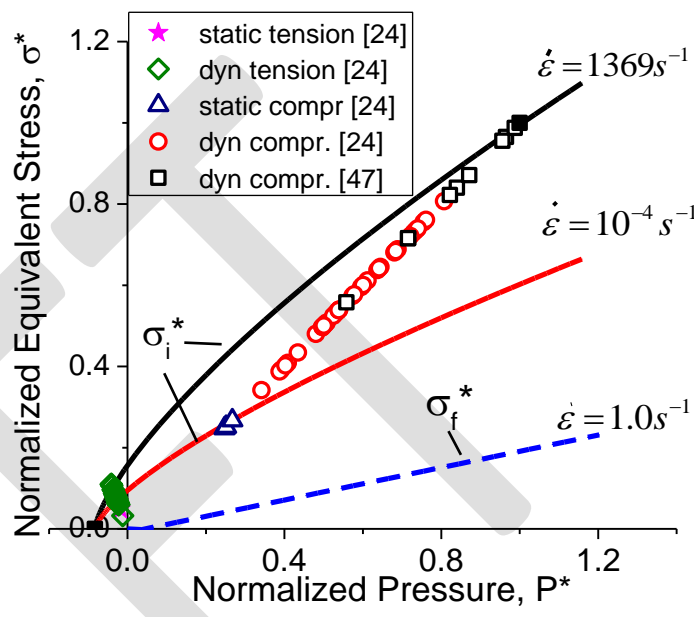

b) Glass strength model of JH2 [47]

Figure 6 Popularly used glass material models

\section{Monolithic Glass Windows}

Monolithic glass windows with annealed glass have been widely used in constructions for decades. To improve window performance, heat-strengthened glass and fully tempered glass are more and more popularly used to substitute traditional annealed glass because of their higher strengths. To reduce the threat from ejecting glass fragments, fully tempered glass are often preferable. The behavior of monolithic glass windows under blast loading and the corresponding glass fragment characteristics are outlined in this section.

\subsection{Monolithic pane response}

\subsubsection{Analytical and numerical studies}

Analytical study on predicting glass pane response generally adopts SDOF method $[6,50,51]$. Based on the assumption that glass pane could deform several 
times of its thickness until failure, non-linear large deflection theory by Timoshenko [52] on thin plate was widely employed by considering both flexural response and membrane effect of glass pane. Load-deflection relation was derived with incorporation of Poisson's ratio of 0.3 for glass [52]. The difficulties were arisen from accurately depicting pane resistance function. Modifications were basically made to the contribution of membrane effect which heavily depended on the level of glass pane planner movement.

With the development of finite element method, numerical method was used to assist the assessment of glass pane response. Pane stress and central deflection were assessed for monolithic glass pane subjected to lateral pressure. Load-deflection curves and load-stress relations for glass panes of different sizes and thicknesses were derived by Moore [7, 53] (Figure 7).

Moore's load-resistance curves were thoroughly adopted by Meyers into his SDOF analysis on monolithic glass window response under blast loading [50]. The failure of glass pane was defined by pane central deflection which results in a maximum tensile stress till failure. 


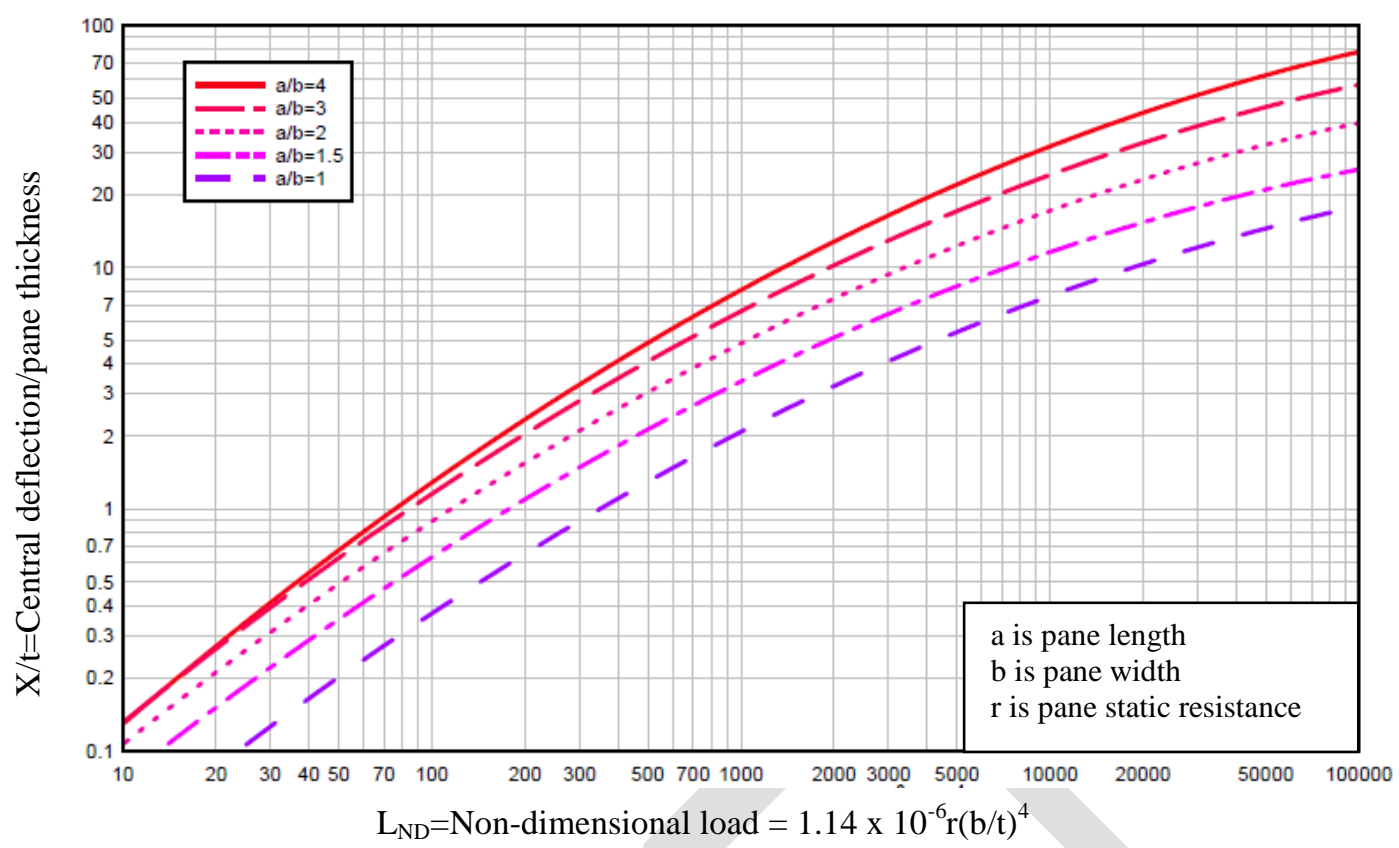

Figure 7 Non-dimensional load-deflection relationships for tempered glass [53]

\subsubsection{Design guides}

UFC 3-340-02 [9] and ASTM E1300 [34] both facilitate with analysis and design of monolithic glass windows. UFC 3-340-02 provides a special section outlining design requirements for blast resistant monolithic tempered glass windows. The UFC code utilizes SDOF method, which basically follows Meyers's analysis [50], to analyze window response under blast loading. However, no damping is considered in the UFC code, while Meyer considered a 5\% global damping in the analysis, which tends to be slightly more conservative in the quasi-static region. Design charts with different combinations of glass dimensions and thicknesses are provided in UFC code to determine the blast resistant capacity of monolithic tempered glass windows. For instance, Figure 8a shows the blast resistance capacity of a 3/8 inch (appr. 10mm) thick and span ratio (long side/short side) $=1.25$ tempered glass pane. For a glass pane of defined short side length (b), the peak pressure and load duration that the window capable of resisting can be determined with the chart. Wise verse, for a specific designed blast load (peak pressure and duration of blast pressure) the maximum pane dimension (short side length, b) can be determined. The ASTM 
standard provides similar design charts with different combinations of window dimensions and thicknesses. For a $6 \mathrm{~mm}$ thick glass pane of certain pane width (short side) and length (long side), the 3-second equivalent blast load that can be resisted by the windows can be found through the chart (Figure 8b). Glass type factor is utilized to consider glass pane fabricated with different types of glass. For a window with heat-strengthened or fully-tempered glass, a glass type factor should be applied to amplify the blast load found in the chart. In ASTM code, the glass pane is simply supported and free to slip in plane. Fully-clamped boundary condition is not considered. It should also be noted that UFC code requires glass pane to be simply supported on four sides, while ASTM standard can be applied to glass pane either simply supported or free to slip in plane and not necessarily on four sides but on two or three sides only.

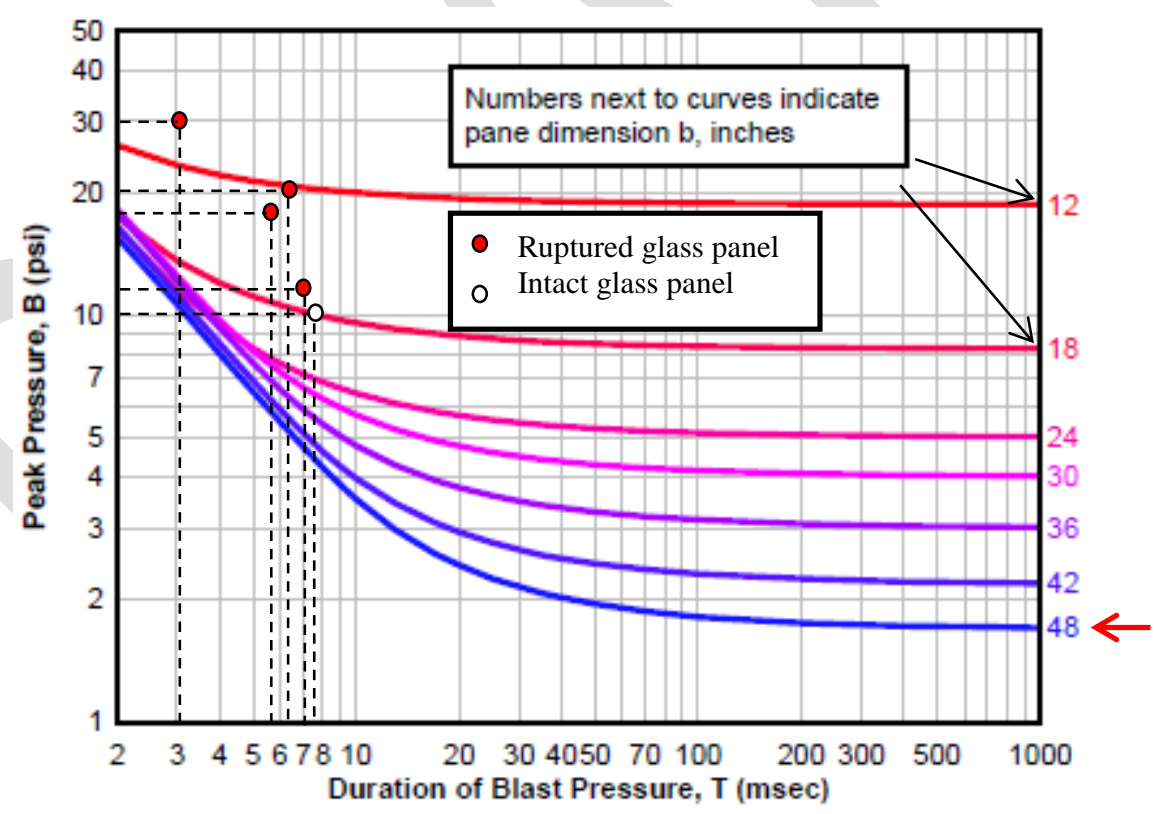

a) UFC 3-340-02 peak blast pressure capacity for tempered glass pane (pane length $a /$ width $b=1.25$, pane thickness $t=3 / 8$ inch, about 9.53 $\mathrm{mm})$ 


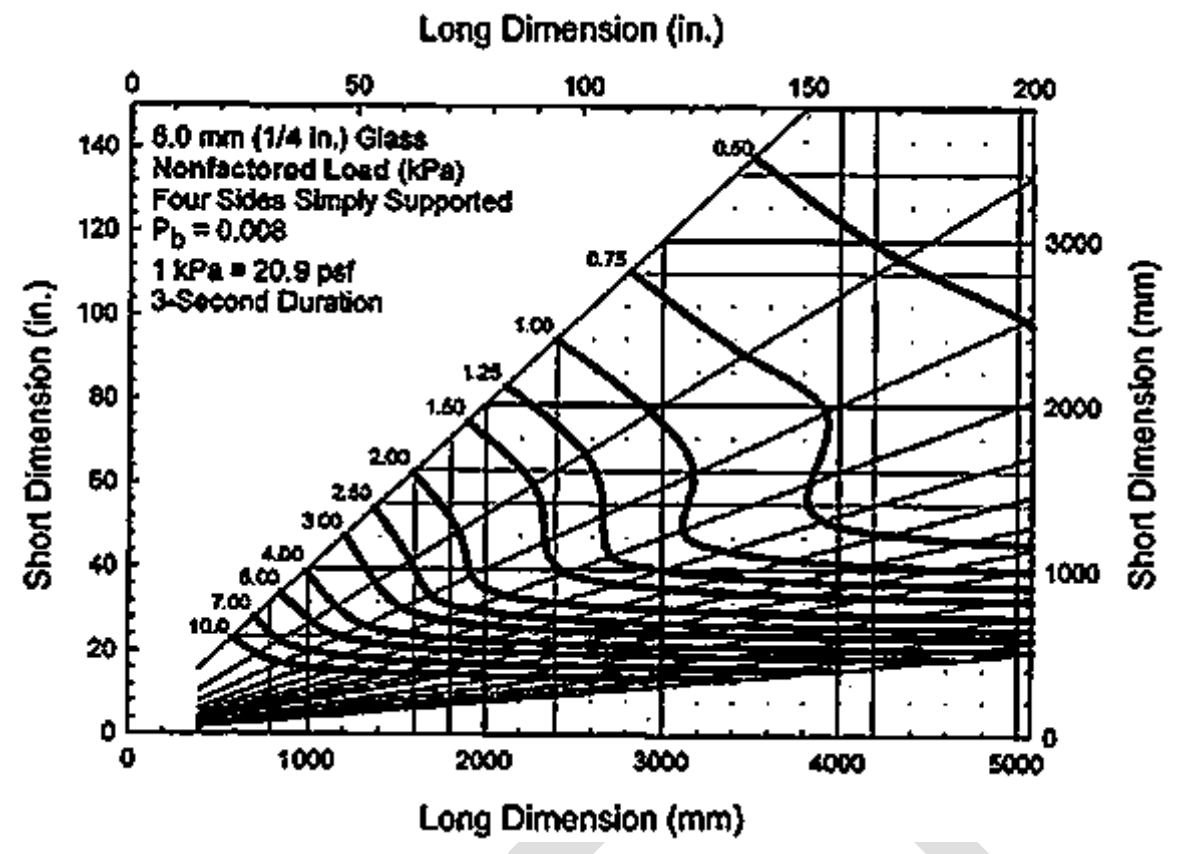

b) ASTM E1300 non-factored load chart for $6 \mathrm{~mm}$ annealed glass with four sides simply supported

Figure 8 Design guidelines for monolithic glass windows by UFC [9] and ASTM [34]

\subsubsection{Experimental investigations}

The above design methods based on non-linear plate theory have been popularly used in design practice for monolithic glazing. However, these methods are not necessarily always accurate. Table 1 lists the recorded peak reflected pressure $\left(\mathrm{P}_{\mathrm{r}}\right)$, duration of blast pressure $\left(\mathrm{t}_{\mathrm{d}}\right)$, and window post-test status for a group of $10 \mathrm{~mm}$ thick monolithic tempered glass panels of dimension $1.5 \mathrm{~m} \times 1.2 \mathrm{~m}$ in recent full-scale field blast tests [17]. As shown in Figure 8a when applying UFC standard to this set of test data $(48 \mathrm{inch}=1.22 \mathrm{~m}, 3 / 8 \mathrm{inch}=9.53 \mathrm{~mm})$, it can be observed that UFC code conservatively predicts all tested panels as 'Rupture' despite Pane 5-1-1 survived a much higher applied blast load in the field test. The conservative estimation by UFC code is mainly because the failure of glass window in UFC code is judged by glass tensile strength. However, as mentioned above recent laboratory tests revealed that glass dynamic tensile strength will be amplified considerably under high strain rate loading. Using the static failure strength of tempered glass is likely to underestimate 
the dynamic glass strength. Therefore, it is necessary to incorporate glass dynamic strength in design code so as to get more accurate predictions.

Moreover, some recent field blast test on $1.5 \mathrm{~m} \times 1.2 \mathrm{~m}$ monolithic tempered glass windows found that the tested glass windows fractured in two unique failure modes, i.e. spherical failure and planer failure pattern (Figure 9a) [17]. Similar observation was also reported by Morison [54]. Analysis on glass window response found that the failure mode of monolithic pane was highly related to the ratio of loading duration over natural period of glass pane. Spherical failure which is related to the predominant flexural response mode tends to occur when the loading duration is large, while planar failure which is related primarily to shear failure mode is more likely to happen when the loading duration is short. Design methods based on SDOF analysis, such as UFC 3-340-02 consider the flexural response of glass pane because the equivalent SDOF system is derived according to the static deflection shape of the structure. Under blast loading with large amplitude and short duration window response and damage are very likely governed by shear failure mode. Since the equivalent SDOF system in the design guides is derived with flexural response assumption, shear failure mode cannot be captured. Therefore, the capability of such design codes in estimating glass window response to impulsive loading is not good. For instance, in Table 1 the failure patterns of Pane 9-1-1, 12-1-1, 10-1-2 and 11-1-2 in the field blast tests were categorized according to high-speed camera images. Despite the design chart from UFC 3-340-02 (Figure 8a) can be used to predict the failure of tested panels, it could not distinguish window failure modes. More field blast tests are still needed to better evaluate the accuracy of the available design chart in the impulsive region with even higher blast pressure and shorter blast duration. It is also worth noting that the monolithic glass panel is very brittle. It normally fractures at very early stage of the 
positive blast pressure. Table 1 also gives $t_{c}$, the time corresponding to the fracture of glass panel captured by high speed camera in the tests.

\begin{tabular}{crcccc}
\hline Pane No. & $\mathrm{P}_{\mathrm{r}}(\mathrm{kPa} / \mathrm{psi})$ & $\begin{array}{c}\mathrm{t}_{\mathrm{d}} \\
(\mathrm{ms})\end{array}$ & $\begin{array}{c}\mathrm{t}_{\mathrm{c}} \\
(\mathrm{ms})\end{array}$ & Status & Failure type \\
\hline $5-1-1$ & $72.9 / 10.6$ & 7.4 & - & Intact & - \\
$5-2-1^{*}$ & $516.1 / 74.8$ & 2.1 & - & Rupture & - \\
$9-1-1$ & $220.0 / 31.9$ & 3.3 & 1.3 & Rupture & Planar \\
$12-1-1$ & $141.5 / 20.5$ & 6.5 & 1.5 & Rupture & Planar \\
$10-1-2$ & $130.1 / 18.9$ & 5.8 & 2.5 & Rupture & Spherical \\
$11-1-2$ & $84.7 / 12.3$ & 7.0 & 2.0 & Rupture & Spherical \\
\hline
\end{tabular}

* Window failure type is not available for Pane No. 5-2-1

Table 1 Summary of test results on monolithic tempered glass windows [17]
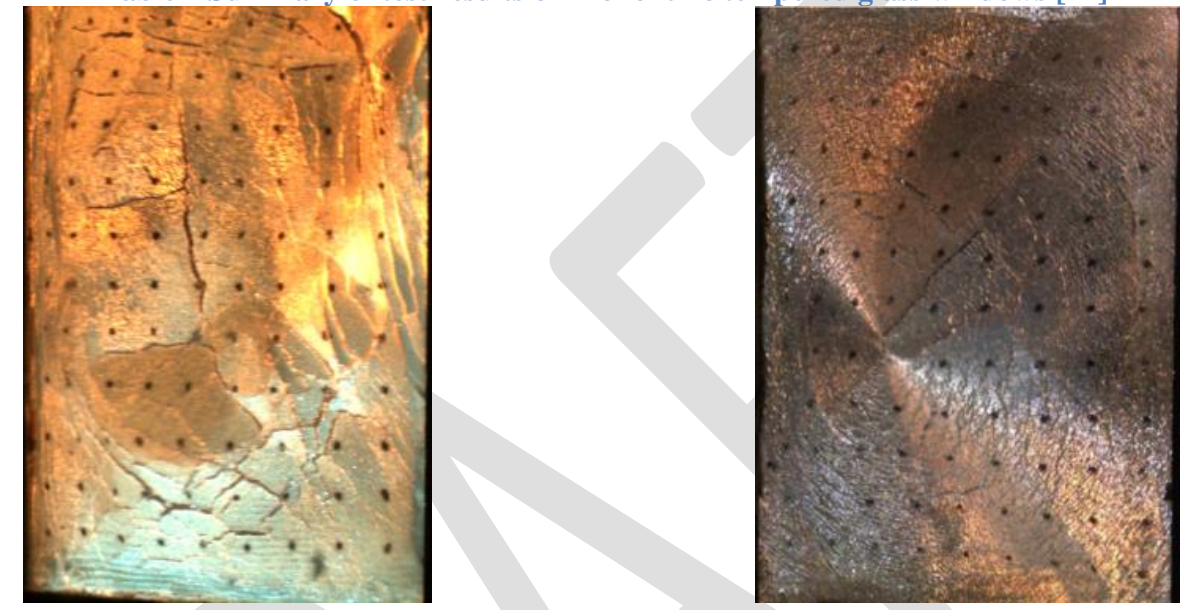

a) Monolithic tempered glass windows [17]
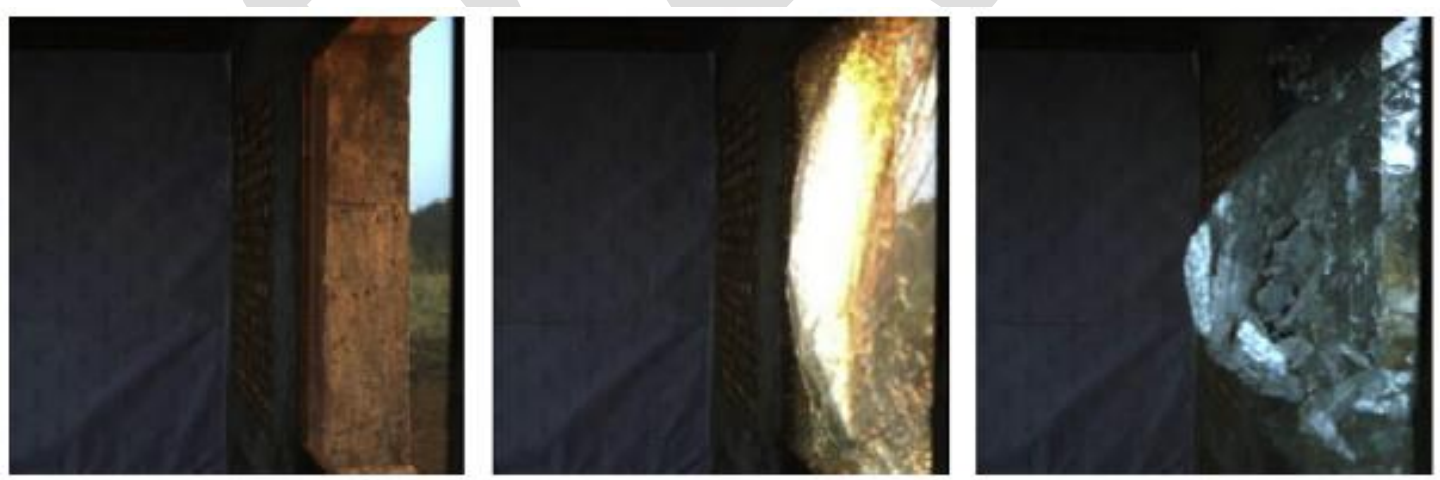

b) Monolithic annealed glass windows [55]

Figure 9 Field blast tests on monolithic tempered [17] and annealed glass windows [55]

A large amount of field blast tests and shock tube tests have been conducted over the past decades $[5,56-58]$, but the amount of testing results available for public assessment is still limited due to security concerns. Meyers et al. [57] reported their shock tube testing results on monolithic tempered glass window of squared and rectangular shapes. The recorded air pressures in the chamber lasted over $150 \mathrm{~ms}$, 
which might be similar to gas explosion but are beyond the scope of blast wave from high explosives. Weissman et al. [58] carried out field blast tests on monolithic annealed glass windows. The windows were arranged either face-on or side-on the direction of blast wave. Window frames made of wood and aluminums were assessed. Empirical design criteria were proposed in terms of the maximum overpressure capacity of glass pane obtained in the blast tests. Peak reflected pressure and glass failure state were reported; however other details such as pressure time history, glass pane response history etc. were not documented. A few more field tests on monolithic glass windows are recently reported. Zhang et al. [17] performed full-scale blast test on monolithic tempered glass windows. Glass window deformation-to-fracture processes were monitored in detail using high-resolution high-speed cameras. Ge et al. [55] carried out field blast tests on monolithic annealed glass windows to investigate fragment behavior. Many commercial blast tests have also been carried out. But these tests are only to validate particular mitigation products and methodologies or to evaluate their efficiencies. There is in general still a lack of testing data on the performance of monolithic glass windows available for public access.

\subsection{Fragment characteristics}

\subsubsection{Design codes and assessment tools}

Properly evaluating and quantifying glass fragment threat from a shattered monolithic glass window has always been a major concern and challenge. GSA TS-01 [59] classifies glass fragment threat based on fragment splash distances into the occupied space. As shown in Figure 10, after a blast incident if the glazing does not break or cracks but retained by the frame the hazard level is rated as 'none'. When fragments enter the space within $1 \mathrm{~m}$ (3.3ft) distance from the window or splashed 
from $1 \mathrm{~m}(3.3 \mathrm{ft})$ to $3 \mathrm{~m}(10 \mathrm{ft})$ range, they are categorized as 'very low' and 'low' hazards respectively. If the glass shards are propelled into the room flying at height lower than $0.6 \mathrm{~m}(2 \mathrm{ft})$ at $3 \mathrm{~m}(10 \mathrm{ft})$ distance, the hazard level is 'medium', and the rest is rated as 'high' hazard. Similar assessment criteria are also provided by British Glazing Hazard Guide Criteria [60], ASTM F 1642 [61] and ISO 16933 [62]. These guides do not take into consideration of the fragment velocity, size, and shape in defining the hazards criteria. Many government agencies such as TNO of Netherlands [63] and US Army Tech Center and US Army Corps of Engineers Protective Design Center are in the process of developing their hazard assessment tools to evaluate ejecting glass fragment threats subjected to blast loading. For example, TNO carried out a series of shock tube tests on monolithic glass windows and monitored glass fragment velocities and sizes. Empirical relation between fragment velocity and reflected impulse was derived and implemented to its fragment hazard prediction module. Since the number of windows tested was limited, the accuracy of this module to predict fragment characteristics from windows of other thicknesses, dimensions and subjected to other combinations of explosive weights and stand-off distances is not known. Due to security concern, these available hazard assessment tools are generally only accessible to military and government agencies and not available for public access. Comparison and evaluation of the accuracies of different hazard assessment tools in predicting glass fragment hazards are therefore not possible. Reliable analytical and numerical models for predicting glass fragmentation process, fragment size, shape and velocity are not available yet. The current practice is still based primarily on empirical relations established from limited testing data to generate fragment hazard module. More experimental studies of glass windows of various dimensions subjected to different blast scenarios are still needed to enrich the 
available pool of testing data so as to provide more reliable fragment hazard assessment tools.

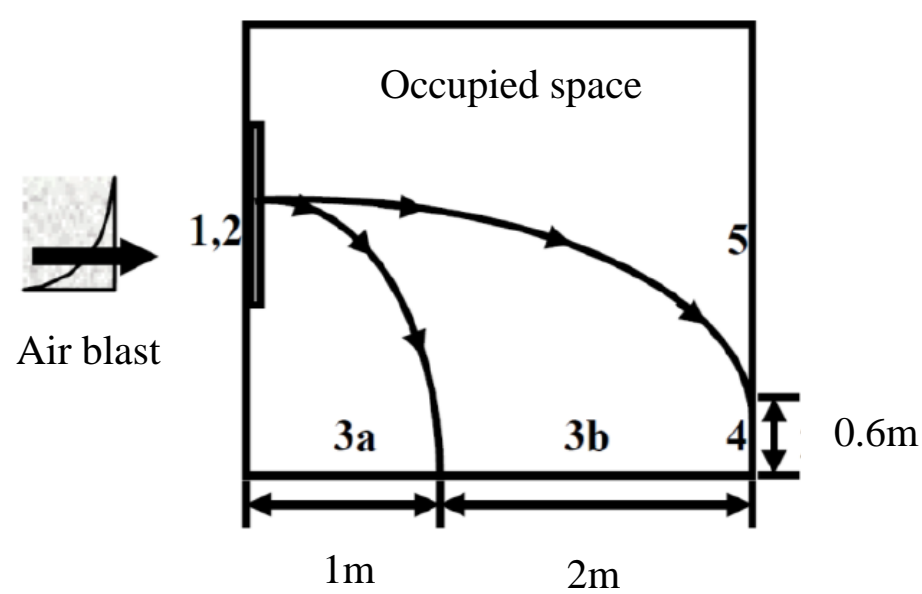

Figure 10 GSA performance conditions for window system response [59]

\subsubsection{Analytical and numerical studies}

Analytical solutions and numerical simulations have also been employed in analyzing glass window fragmentation process. Based on strain energy coupled with damage, Zhang et al. [64] formulated an analytical model for predicting fragment size and ejection velocity. The fragment ejection velocity was related to strain rate which was regarded suitable to investigate dynamic fragmentation process. Ge et al. [55] derived semi-analytical solutions to estimate glass fragment velocity and splash distance (Figure 11). The derivation was also based on energy principles, and the constants involved in the formula were determined by their field blast test on monolithic annealed glass. Numerical methods were widely used to simulate glass window responses to blast and impact loads [38, 65-68]. However successful numerical models in simulating glass fragmentation are very limited. The existing numerical approaches have inherited difficulties in predicting structural fragmentations. The SDOF approach can only predict the overall window responses. The finite element method employs an erosion criterion to erode away elements to 
avoid element tangling, which results in loss of fractured glass mass and also violates the principle of energy conservation. The meshless method and discrete element method avoid erosion, but the particle sizes and weak sections that will lead to structure breakage are pre-determined. Therefore, all these methods do not necessarily lead to reliable predictions of fragment size, launching velocity and distance. Despite some new numerical methods are available to simulate glass pane fracture and fragmentation process, such as X-FEM, SPH, DDA etc., successful applications of numerical approaches in reliably predicting glass fragmentation are still rare in the literature. Evaluations and understandings on glass fragment properties are therefore still heavily based on experimental investigations.

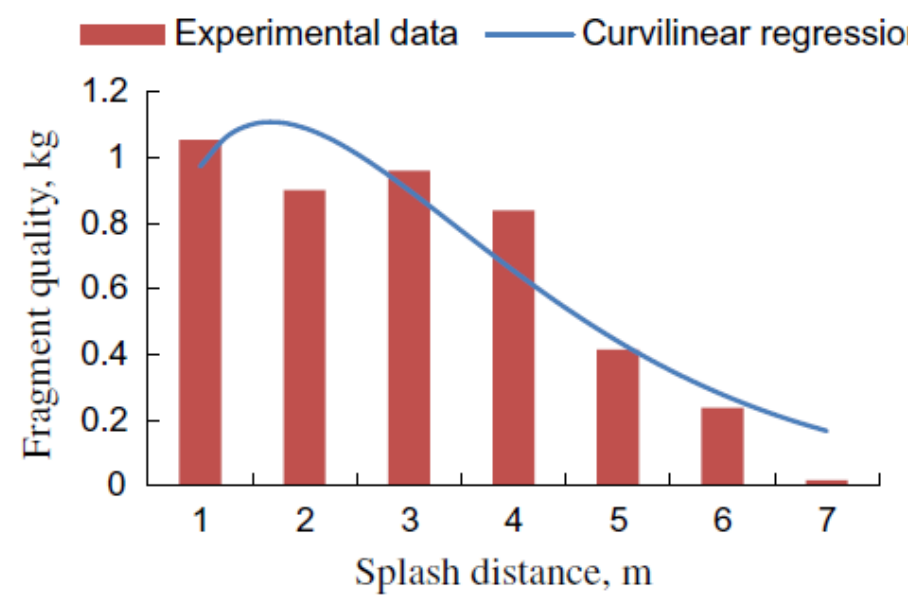

Figure 11 Theoretical and experimental studies on annealed glass fragment splash distance [55]

\subsubsection{Experimental investigation}

Many experimental investigations on glass fragment characteristics were reported over the years. For instance, Doormaal et al. [63] tested $8 \mathrm{~mm}$ thick annealed glass windows and provided the relationships of the maximum fragment velocity and blast reflected pressure and impulse. Locke and Unikowski [69] carried out pendulum impact tests on glass windows. Fragment distribution was investigated by collecting glass fragments splashed on the ground. More systematic experimental investigations on annealed glass windows were reported by Fletcher [70] and Iverson [51], who 
respectively studied fragment characteristics and the related fragment velocity, mass, spatial density with blast reflected pressure, and also assessed biological impact from ejecting window fragments. It was concluded that, as expected, the splash distance and fragment ejecting velocity are proportional to the magnitude of reflected blast pressure and impulse.

Fragment threats from fully tempered glass windows are generally ignored because under static or low-speed impact tempered glass pane normally shatters into numerous small and fine cubicles which impose limited threats. However, under blast loading this is not necessarily true. As discussed in Section 2, under blast loading fully tempered glass could still break into large and jagged pieces which impose considerable fragment threats to residents. The concern was experimentally proofed by recent field blast test [71]. Bogosian and Avanessian also carried out full-scale field tests to evaluate the blunt trauma lethality of monolithic tempered glass [72]. As shown in Figure 12a, large and jagged fragments resulted in serious blunt trauma in residents behind monolithic tempered glass windows. The fragments characteristics such as ejected fragment mass, fragment size, shape, number, spatial density, and launching velocity were systematically studied by Zhang et al. based on their field blast tests [71]. It was found that pane failure pattern would influence fragment shape, where more sharp and slender fragments were produced with spherical failure while more round and squared fragments were generated with planar failure (Figure 12b). It is also worth noting that negative pressure was found to significantly influence fragment ejecting velocity and splash distribution, which led to glass fragments propelled and splashed in front of windows. More experiments are still needed to augment the testing database for better understanding of glass fragment characteristics under blast loading. 

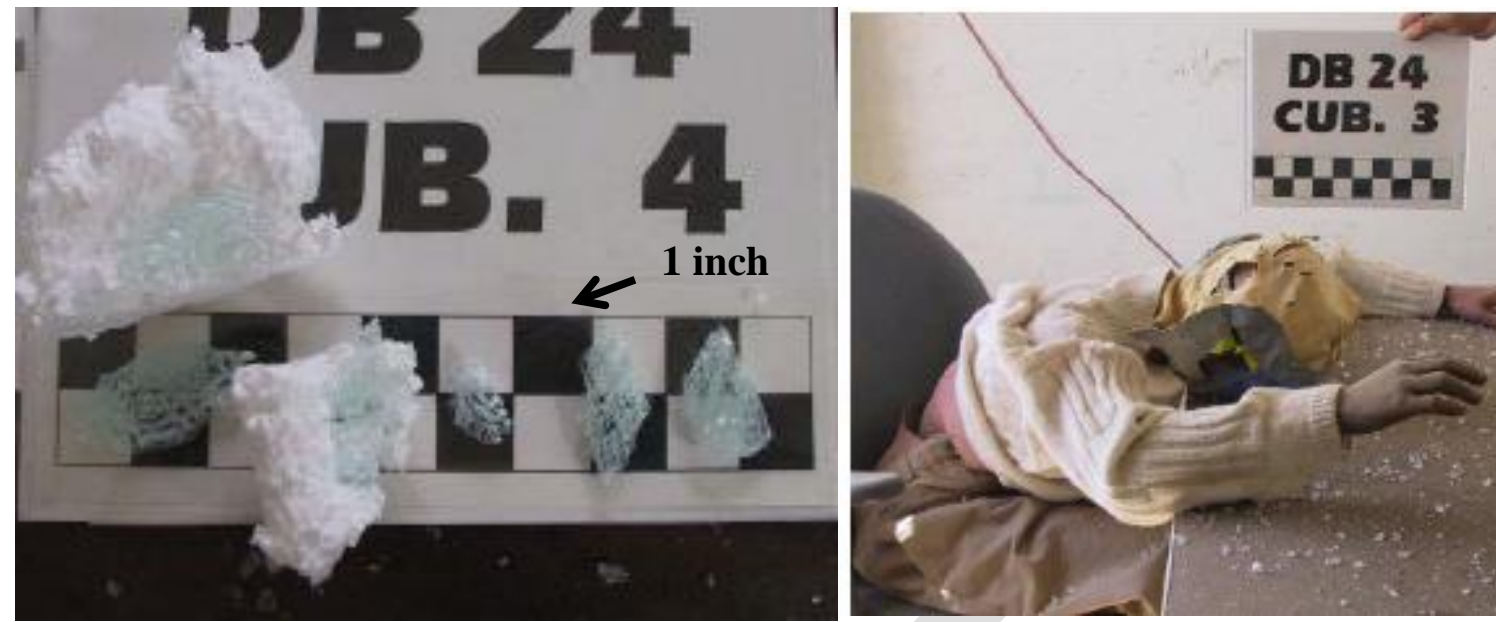

a) Blunt trauma lethality of tempered glass [72]
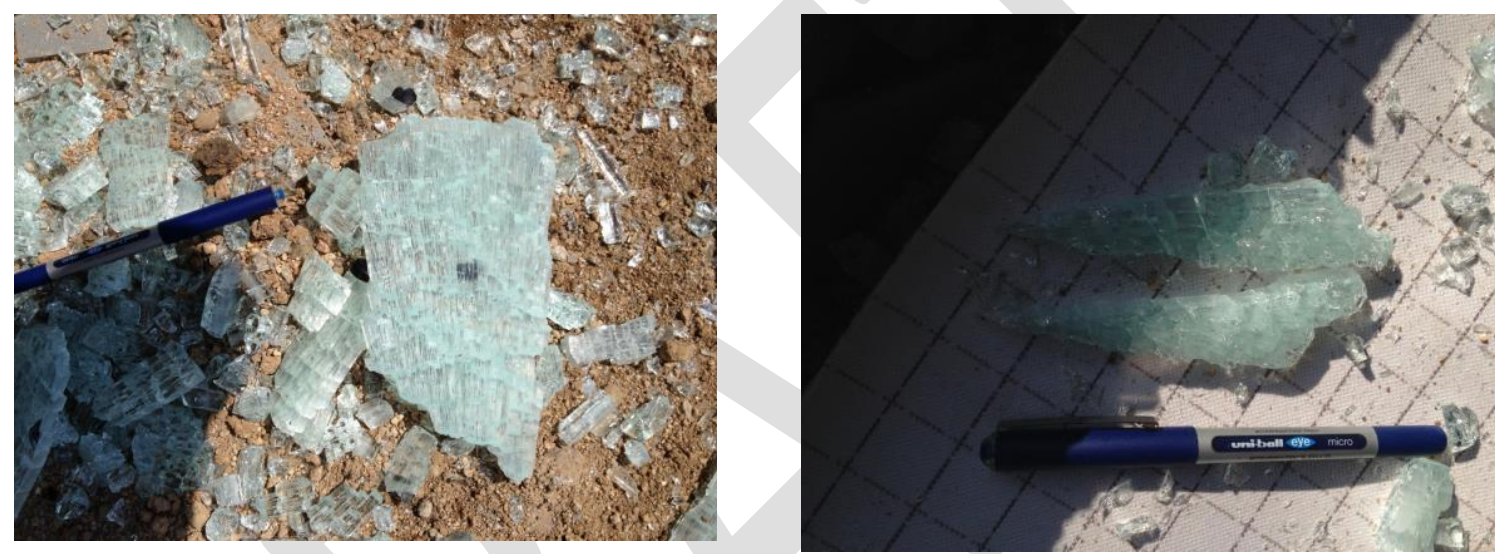

b) Large pieces of squared and slender fragments from tempered glass windows [71]

Figure 12 Glass fragments from monolithic tempered glass panes

\section{Laminated Glass Windows}

Laminated glass is widely used for blast resistant glazing to mitigate the hazards from ejecting glass fragments. Laminated glass window is made of two or more layers of glass panes laminated together with one or multiple plies of polymer interlayers. The aim of laminated glass is to hold shattered glass shards together and deforms with its substantial ductility as a continuous membrane to dissipate the imposed energy (Figure 13). Before analyzing laminated pane response, it is necessary to properly understand interlayer dynamic material properties. 


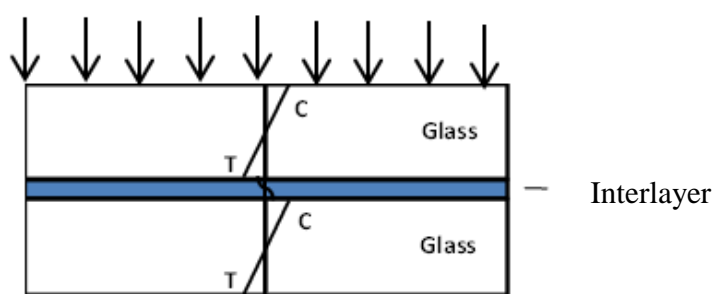

a) Pre-glass ply breakage

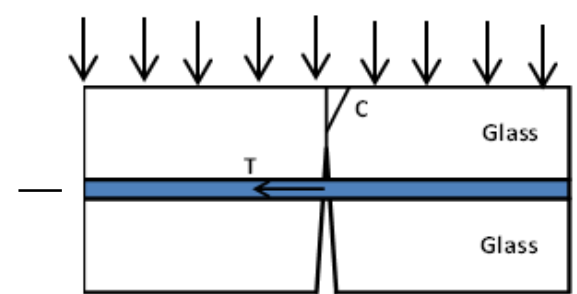

b) Post-glass ply breakage

Figure 13 Role of interlayer in laminated glass

\subsection{Interlayer material properties}

Commonly used interlayer materials include polyvinyl butyral (PVB), ionoplast polymer and ethylene acetate (EVA). Each of these polymer materials has specific transition temperature range for engineering applications, and the mechanical properties of different material also vary largely [73]. Furthermore, recent laboratory tests found the dynamic material behaviors of many interlayer materials differ from their static behaviors. The mechanical properties of two most commonly used interlayer materials for laminated glass, PVB and ionoplast polymer are outlined in the following section.

\subsubsection{PVB}

PVB is a polymer material with outstanding mechanical properties which has been primarily used as interlayer material for laminated glass. The mechanical behavior of PVB has been proven to be complicated, which is highly nonlinear, time-dependent, and being capable of undergoing substantial extension.

The behavior of PVB at small-strain was intensively investigated for the analysis of pre-glass crack response of laminated glass pane. A viscoelastic model with a generalized Maxwell series is generally introduced to account for the time-dependent shear modulus [74-76] (Figure 14a). The influence of temperature is considered with Williams-Landel-Ferry equation to shift shear modulus of different temperatures [76]. 


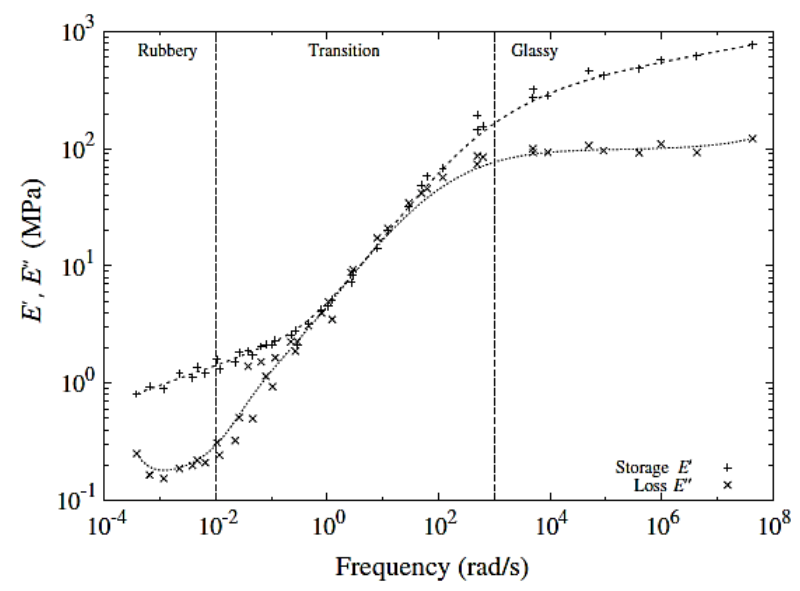

a) Modulus vs. frequency at $20^{\circ} \mathrm{C}$ [76]

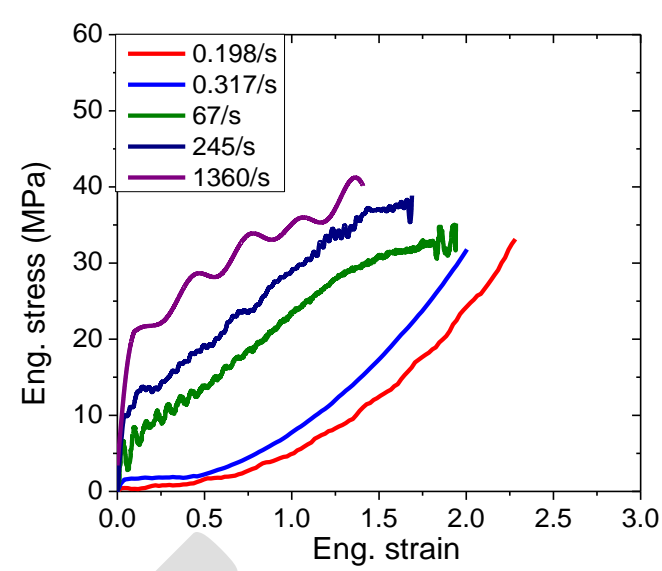

b) PVB stress-strain curves [77]

Figure 14 Mechanical properties of PVB

The mechanical behavior of PVB at large strain was studied at both quasi-static and dynamic states $[54,76-80]$. Laboratory tests reveal that PVB shows viscoelastic material properties at low strain rates and is loading rate dependent. The dynamic tensile behavior of PVB was recently investigated up to a strain rate of over $1360 \mathrm{~s}^{-1}$ [77]. Dynamic tensile tests found the dynamic material properties of PVB differ significantly from its quasi-static behavior, which show elasto-plastic like stress-strain curves with a steep initial rise in stress followed by a decrease in modulus. The dynamic response of PVB is also characterized with time-dependence. As shown in Figure 14b, the initial modulus, 'yield stress', and failure stress will be amplified at increased strain rates. As strain rate increases PVB becomes less ductile. It can therefore be found that the simplification of using PVB static properties to analyze laminated glass response under blast load will lead to significant inaccuracy; especially the ductility of interlayer is to be overestimated. Instead of employing a viscoelastic model with PVB static material properties, recently some researchers used strain-rate dependent elastic plastic material model or bi-linear elastic model for PVB interlayer when modeling laminated glass response under blast and impact loadings [38, 65]. In general, good numerical results were reported when modeling the forced vibration of the laminated glass windows. 


\subsubsection{Ionoplast}

Commonly used ionoplast material such as SGP (SentryGlas®Plus produced by DuPont) has been developed and introduced as interlayer material for laminated glass to improve its post-glass breakage behavior. Compared to traditional PVB interlayer which is soft and ductile (with failure strain of about 200\%), SGP offers higher tearing strength, better rigidity, and larger failure strain.

The mechanical properties of SGP at different strain rates were investigated through laboratory tests [80-82]. As shown in Figure 15b, under uniaxial tensile loading SGP exhibits elasto-plastic like material properties, which are also strain-rate sensitive. The 'yield stress', initial modulus, failure strength will increase with strain rates, but the ductility diminishes quickly under elevated strain rates from about $400 \%$ at quasi-static state to only $150 \%$ at a strain rate of $2000 \mathrm{~s}^{-1}$ [82].

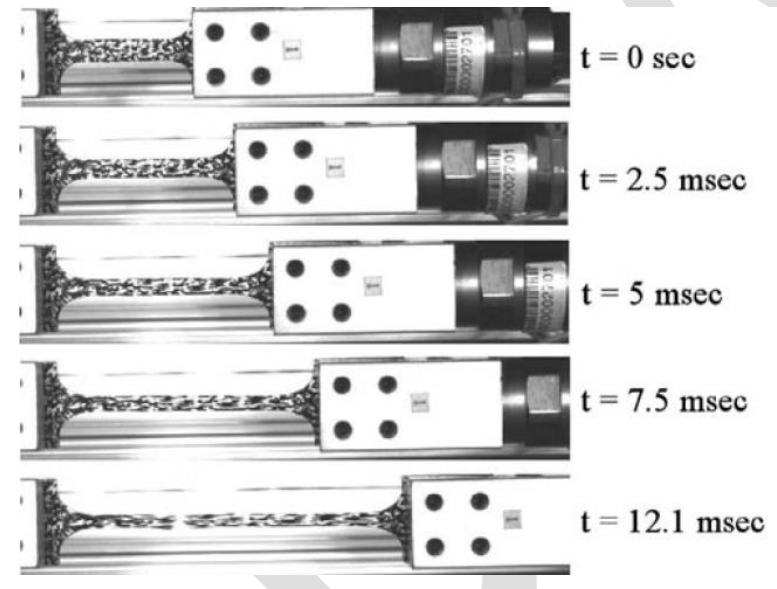

a) High speed tensile test [80]

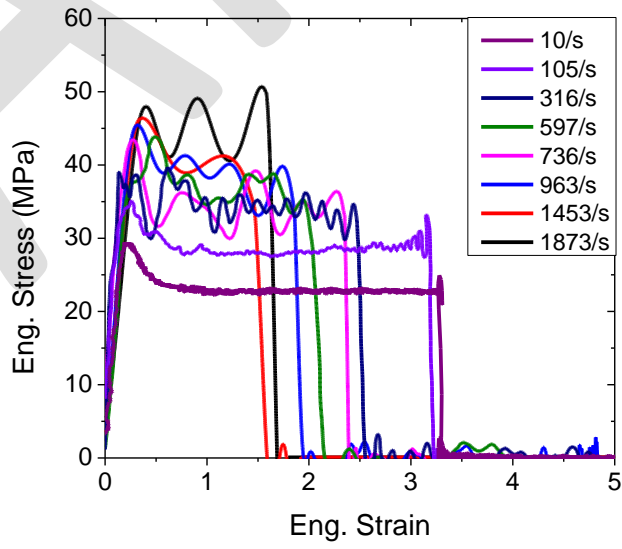

c) SGP stress-strain curves [82]

Figure 15 High speed tensile test and SGP engineering stress-strain curves

For both PVB and SGP, albeit the elasto-plastic like behavior that can be observed from the stress-strain curves (Figure $14 \mathrm{~b}$ and Figure 15b), many researchers mentioned the recoveries of deformation in the tested specimens after unloading [76, 77,83 ], indicating the viscoelastic nature of such materials. In this case, if unloading response of a laminated pane needs to be considered, simply using an elasto-plastic 
material model for either PVB or SPG may not be appropriate, which will lead to incorrect prediction of laminated pane behaviors. On the contrary, plastic deformations were reported by some researchers on PVB $[78,80]$. Nevertheless, it should be noted that plastic behavior of material can only be characterized if the remaining strain during unloading is measured [73]. There is still a lack of testing data on the unloading behavior of the above polymer materials. To the authors' knowledge, such testing technique is still not available for high-rate dynamic unloading. Therefore, the observed viscoelastic or plastic behavior of these polymer materials still needs further investigation. Without testing data on unloading phase, proper modeling of the dynamic unloading behavior of these polymer materials is still not feasible. Testing results on EVA at high strain rates cannot be found in literature. Testings are required to reveal its mechanical behaviour at various strain rates.

\subsection{Numerical and analytical studies}

The deformation-to-failure process of laminated glass windows under lateral loading is normally described in five phases [38, 73] (Figure 16): (1) glass plies deform elastically; (2) the outer glass ply breaks; (3) the inner glass ply cracks; (4) the interlayer deforms as a membrane; and (5) the interlayer fails by reaching its failure strength or by cutting of glass shards.

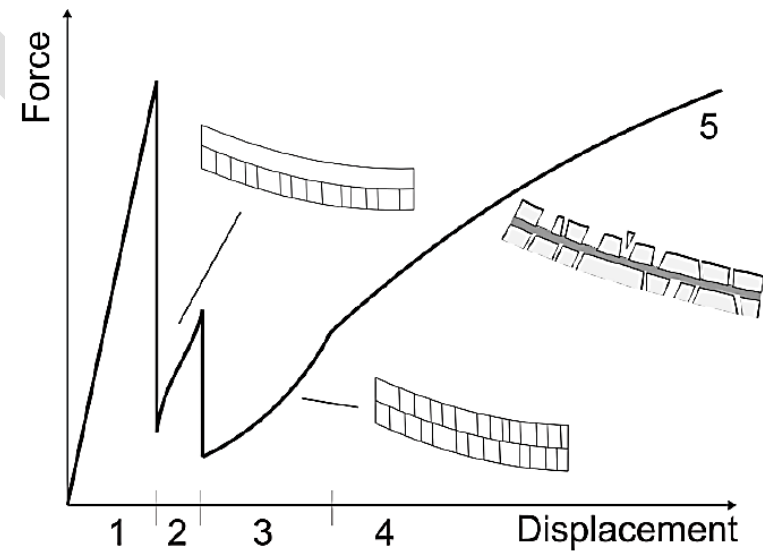


The behaviour of PVB laminated glass pane before glass cracks have been extensively studied by some researchers $[40,54,74]$. A major dispute was on the amount of shear force that can be transferred through the polymer interlayer in the composite laminated panel. Minor differences were found in pane deflection and principal stress between laminated glass pane and monolithic glass of the same thickness [40]. When strain rate effect is considered for interlayer, the tensile stress on the outer glass ply was marginally higher than that of an equivalent monolithic glass pane [74]. As Morison summarized and commented that regardless of the stress distribution in the interlayer, the failure probability of laminated glass pane hardly alters [83].

The response of laminated glass pane after glass crack is major concerns when studying the laminated glass window vulnerability under blast loading. Numerical methods have been intensively used to model laminated glass windows. Larcher et al. evaluated the applicability of three dimensional (3D) finite element model, shell element model, and smear model in modelling laminated glass [38]. It was concluded that the detailed finite element model with solid element could give best prediction of laminated glass response after glass cracks. The other two methods yield reasonable predictions before glass ply breaks. Many detailed 3D models of laminated glass windows have been built in the past $[38-41,65,67,84,85]$. It should be noted that similar to the case in modelling monolithic glazing, accurately simulate glass ply breakage for laminated glass windows is still a challenge. Traditional methods such as FEM suffer inherited difficulties in properly predicting glass cracking. Moreover, the large deformation of the interlayer material could result in element distortion in finite element model. The Poisson's ratio of PVB is approaching 0.5, which could lead to singularity problem as well. Careful modelling and proper verification of numerical 
models should be made when using numerical methods. Some numerical models using discrete element method (DEM) and smooth particle hydrodynamics (SPH) method were also generated for laminated glass panes in the past few years [86-88]. With recent understanding of dynamic properties of glass and interlayer material, a few numerical models adopt dynamic material models instead of static material properties $[65,67]$.

With the wide application of numerical methods, the failure modes of laminated panes under blast loadings with different combinations of pressure and impulse were examined. The influencing factors such as glass thickness, PVB thickness, glass strength variation, boundary condition, and pane size were systematically studied. Many Pressure-Impulse diagrams were generated by different researchers $[65,67$, 84]. It is worth noting that the pressure and impulse asymptotes of P-I curves from different authors vary, especially for the impulsive region (Figure 17). This is mainly because of different laminated pane failure criteria adopted, such as a maximum inplane strain [89], rupture of interlayer [65, 67], and/or maximum pane central deflection. Current design practise based on SDOF method normally uses the ratio of central deflection over window short span to assess the window failure. Quasi-static waterbag tests found $7.52 \mathrm{~mm}$ laminated glass pane $(1.52 \mathrm{~mm}$ thick interlayer) fails with a deflection over span ratio of $27.8 \%$ [25]. In blast tests, laminated glass windows were found not failed at deflection ratios up to $32 \%$. 


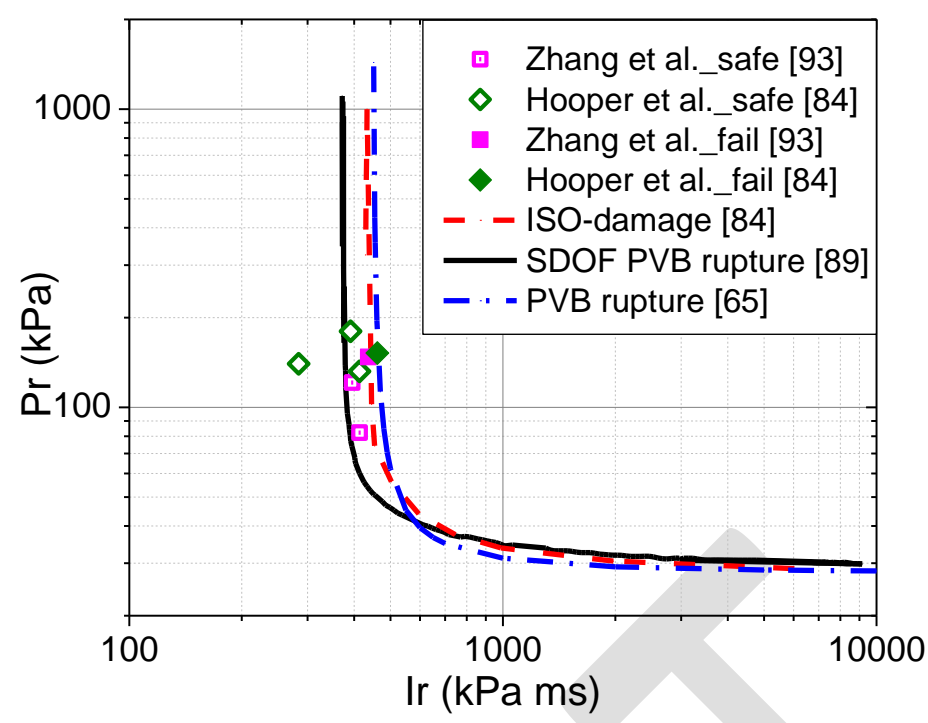

Figure 17 Comparison of P-I diagrams with field testing data for $1.5 \mathrm{~m} \times 1.2 \mathrm{~m}$ laminated glass window

If a laminated glass pane could survive the positive phase of a blast loading, the rebound could still be critical. Teich and Gebbeken [90] conducted parametric analysis using SDOF model to study the effect of negative overpressure on window response. It was found that with certain combinations of scaled distance and structure natural period, inclusion of negative pressure could lead to structure central deflection up to an order of magnitude higher than that under the positive phase. Krauthammer and Altenberg [91] also simplified a monolithic glass pane into a SDOF model. Their results showed the possibility for the glass pane to survive the positive blast pressure but rupture during rebound as a result of negative overpressure. For laminated glass windows, on rebound the pane will exhibit an initial elastic recovery of deformation followed by a slack stage with the cracked glass shards snap. Re-loading and further stretching could occur under the effect of negative pressure. Interaction between blast wave and cracked laminated glass pane makes the slack stage super-critically damped [25]. Reliable numerical or analytical studies on the response of laminated glass window during rebound are not found in the literature. As mentioned in Section 4.1, this is mainly due to the lack of testing data on unloading behaviour of interlayer 
materials at high strain rates. Current understandings are heavily relying on interpretation of high-speed camera images in blast tests.

\subsection{Design codes}

Major design guides such as UFC 3-340-02 [9] and Glazing Hazard Guide [12] by Security Facilities Executives (SFE) simplify the window structure to a SDOF system. Both guides employ large deflection theory to treat the pre-crack behaviour of laminated glass. After glass cracks, the window can be idealized as a flexible membrane. The equivalent load-mass factors and the resistance functions are obtained by analytical approach or based on testing data [92]. The accuracies of estimations from these SDOF models differ. Variation was mainly arisen from different resistance functions. As shown in Figure 18, the resistance function determined from quasi-static waterbag test varies significantly from that derived using dynamic material properties of PVB interlayer. SFE's design guideline utilizes the static resistance function [12]. Through carrying out dynamic tests Morison derived a very different resistance function [54]. Zhang et al. [93] compared and evaluated the accuracies of the two design standards in estimating laminated glass window responses under low and large level blast loads. Under low level impulsive load, the two standards were found to give good predictions of panel responses obtained in laboratory pendulum airbag impact tests. This is because the two resistance-curves define similar window resistance when window deflection is small. However, under high level blast load when panel central deflection is large, UFC code yields much larger deflection than SFE's guideline because much less resistance are defined by UFC code when window deflection level is large. The prediction of UFC code with the dynamic resistance function was found more reliable as compared to the field testing result on laminated glass windows than that of the SFE with the static resistance function. The variation 
of the two design standards in predicting laminated glass window response is also due to the difficulty in accounting for the residual resistance of progressively cracked glass. The load-mass factor adopted for the SDOF model may therefore not be a constant value as in classic theory [94]

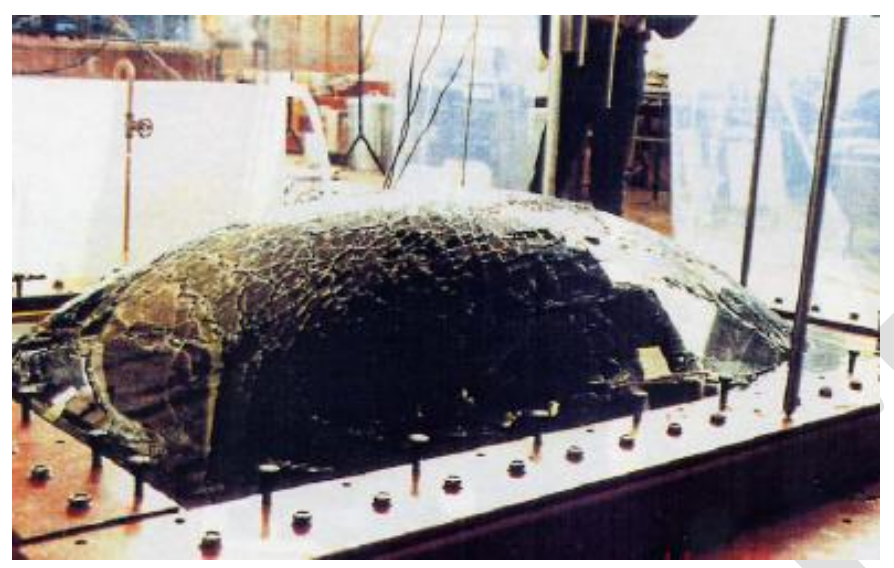

a) Quasi-static waterbag test [92]

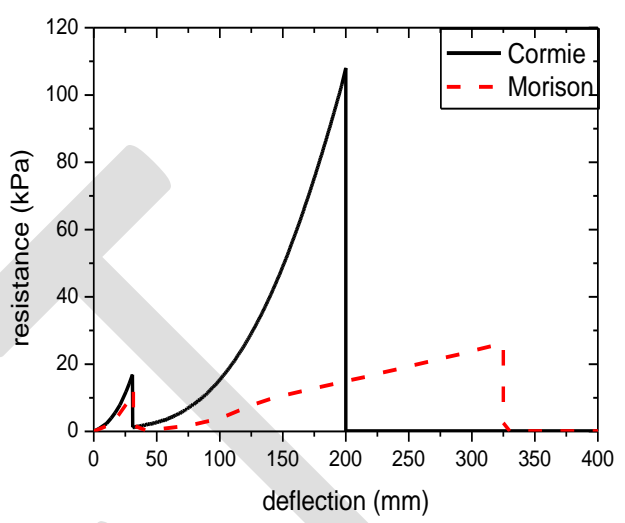

b) Different resistance functions for laminated glass

Figure 18 Quasi-static waterbag test [92] and different resistance-deflection functions

Apart from the above two design guides, ASTM F2248 [10] (in practice with

E1300 [34]) and UFC 4-010-01 [95] are also facilitated with blast resistant glazing design. ASTM F2248 specifies an equivalent 3-second design load (Figure 19) to use with ASTM E1300 to determine the thickness of laminated glass windows. Glass failure prediction model with failure probability of 0.008 is used for glass, and the glass pane is designed to 'break safely'. The maximum central deflection of the laminated pane is calculated using Vallabhan-Wang nonlinear plate method and an equivalent effective pane thickness. UFC 4-010-01 provides no specific analysis guidelines for glass windows to resist blast loads but recommends referring to ASTM F2248. 


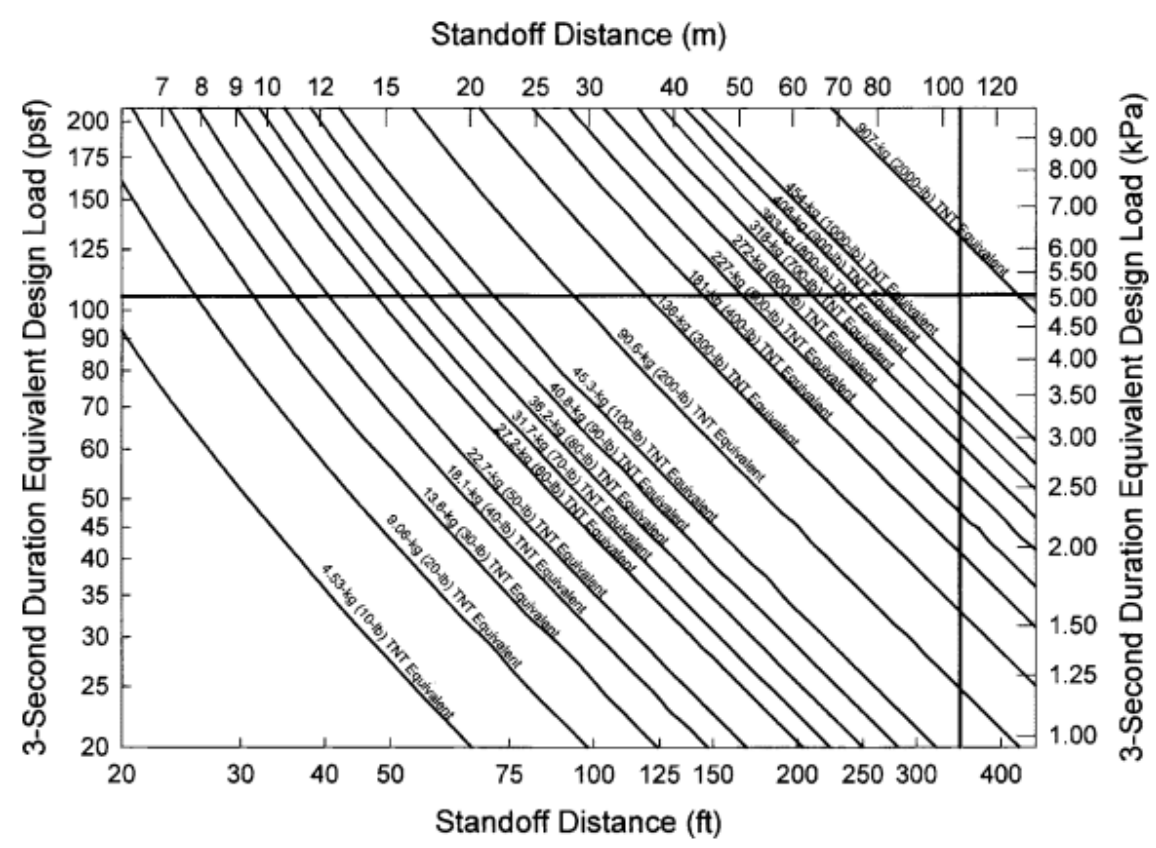

Figure 19 Determination of 3-second equivalent blast load by ASTM F2248 [10]

\subsection{Experimental investigation}

Many laboratory and field blast tests were reported in the literature on laminated glass window responses to impulsive and blast loading [84, 93, 96]. For instance, Kranzer et al. [96] tested $7.52 \mathrm{~mm}$ laminated glass windows subjected to small-scale explosions. Hooper et al. [84] conducted full-scale blast test on $7.52 \mathrm{~mm}$ laminated glass windows with interlayer and boundary failures. Zhang et al. [93] carried out pendulum airbag impact test and field blast test to evaluate the accuracies of available design standards and popularly used SDOF methods. Testing results and analysis show ASTM code tends to largely underestimate laminated pane response. UFC 3340-02 and other SDOF-based approach [12] give reliable predictions when the deflection level is relatively small. Under strong blast loading which results in large pane deflection, most SDOF models underestimate pane response due to the adoption of static resistance function in most analyses. As mentioned above the progressive cracking of glass plies leads to the change of load-mass factors for SDOF analysis. Morison [54] coupled the load-mass factors of SDOF model with different pane 
deflection levels. The modified method was found to give better prediction. However, due to the irregular cracking pattern of glass plies under different blast loads, it sometimes overestimates laminated pane response.

Some observations from laboratory and field blast tests are worth mentioning. Firstly, according to previous field blast tests some researchers pointed out that glass delamination from PVB interlayer is hardly a potential threat, because only very few fractured glass shards delaminated at pane corners were reported [84]. Secondly, a thicker glass pane contributes to better blast resistance of the laminated glass pane. This is because of the significant increase in pane flexural stiffness and inertia resistance when using a thicker glass pane. Nevertheless, it should also be noted that a laminated pane with thick glass could lead to larger reaction to window frame and substructure. To achieve better blast performance, strengthening window frame and substructure is normally required for laminated pane with thicker glass panes. Thirdly, the effect of interlayer thickness on laminated pane maximum deflection is not significant. Similar levels of maximum central deflections were recorded on laminated glass panes with different thicknesses of interlayers [93], indicating increasing the interlayer thickness does not significantly contribute to glass pane stiffness. However, a thicker interlayer helps to reduce interlayer rupture when subjected to blast loading.
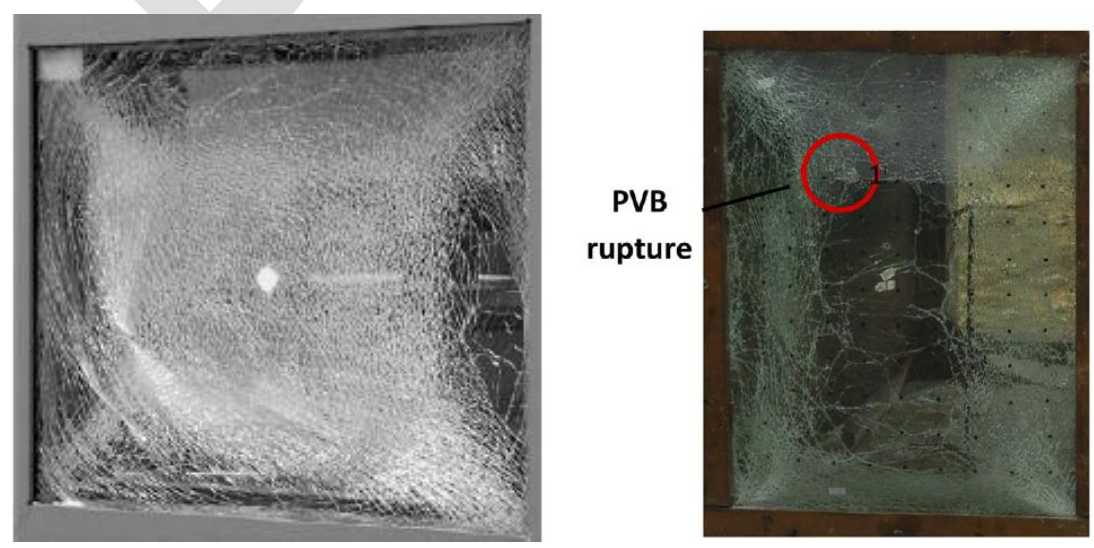
a) Glass crack only [96]

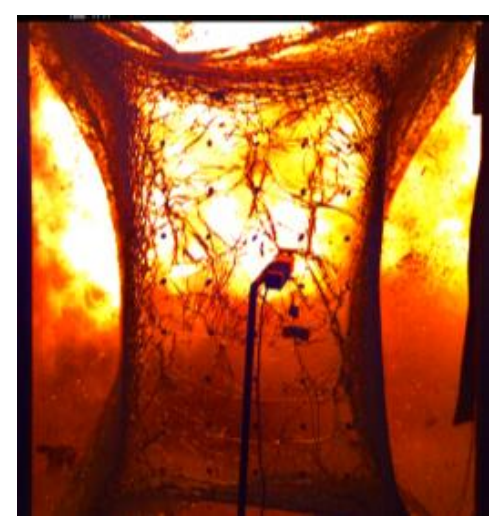

c) Boundary failure [93] b) PVB rupture [93]

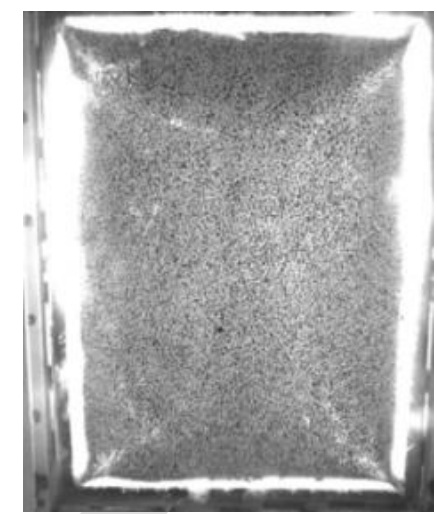

d) Boundary failure [84]

Figure 20 Different failure modes of laminated glass window in blast tests

The restrain from window frame is another concern when designing laminated glass windows. Laminated glass pane is embedded in window frames with and without gaskets in the bite. Structural silicone is commonly used to add bonding strength. Providing the window frame is properly designed, the reaction forces perpendicular to the plane of glass pane can be estimated using SDOF analysis [25]. Some recent shock tube test and field blast test reported the measured perpendicular forces. The researchers either glued strain gauges to the steel frame [84] or employed tri-axial load cell on window frame to track reaction force directly [97]. Different from monolithic glass window, after glass plies crack the deformation of laminated pane and the substantial membrane effect tend to pull the cracked laminated glass panel out of the frame. As evidenced in Figure 20c and d, under air blast wave the entire shattered laminated panes were totally pulled out of the window frame and propelled into the testing cube. Interlayer tearing was not found on any of these glass panes with pull-out failure. A sufficient bite depth and anchorage from the window frame is therefore needed when designing laminated glass windows. Experimental quantification of the in-plane reaction is still not documented. Some UK testing data indicate that for a $1.55 \mathrm{~m} \times 1.25 \mathrm{~m}$ laminated pane a $30 \mathrm{~mm}$ bite is required to reliably 
anchor the panel into the frame [25]. By evaluating most recent laboratory and field tests on laminated glass windows, Zhang et al. [98] studied the effect of frame restrain effect with various bite depth subjected to different blast loading scenarios. Increasing bite depth was found to greatly improve the frame restraint to laminated glass pane against pull-out failure. Applying structural silicone resin to the gap between steel frame and the glass pane help to improve the bonding and mitigate pull-out failure. However, there is still no systematic study yet on the effectiveness of silicone resin.

\section{Mitigation retrofit}

Different techniques and materials are available to improve glass window's blast resistant capability. General practices include replacing low strength-annealed glass with high-strength heat-strengthened glass or fully tempered glass, strengthening window frame and mullion, apply security film, and installing catch system, etc. Lin et al. [99] conducted an intensive review on available window strengthening techniques. With better understanding about the response and failure of glass windows, more mitigation methods have been proposed in recent years. Some selected mitigation retrofits are discussed herein.

\subsection{Security film}

Applying security film to the interior surface of glass windows is a straightforward retrofit especially for existing windows. Security film is normally made of polyester between $0.2 \mathrm{~mm}$ to $0.4 \mathrm{~mm}$ thick, which will hold the shattered glass shards in a manner like laminated glass to reduce the hazards of flying glass shards [99]. For easy application, daylight film can be installed on glass pane without any attachment to window frame or mullions. It is quick, unobtrusive, and relatively inexpensive. However, in a blast incident the shattered glass shards might be hold together by the film and fly entirely towards the residence inside [72] (Figure 21b). 
The potential of laceration by jagged glass shards could be reduced, but the heavy flying pane would pose significant threats. Improvement can be made by extending the film edge into the bite of frame (wet-glazed film in Figure 21a) so as to strengthen glass pane against shear failure near the frames, or anchor the extended film to window frame or other attachment devices, such as bolted to the walls (mechanically anchored film in Figure 21a). Applying security film can be an effective retrofit for minimizing the hazard from fractured glass windows. Proper design is required to achieve the desired blast resistant capacity.

\section{Daylight film}

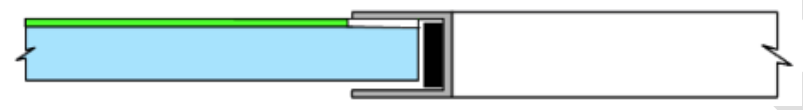

Wet-glazed film

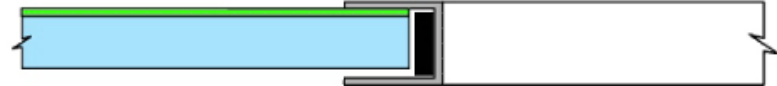

Mechanically anchored film

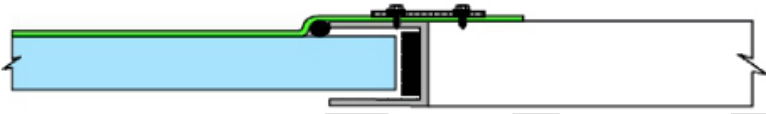

a) Retrofit measures with security films [100]

Figure 21 Security film and field validation test

\subsection{Catch system}

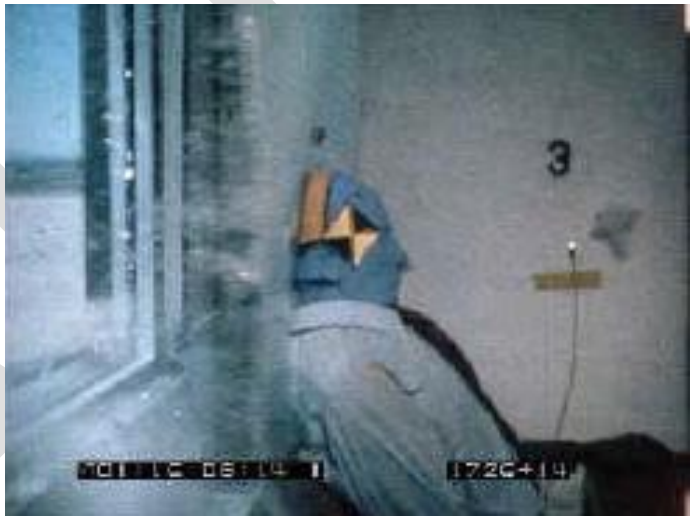

b) Field test on daylight film [72]

Catch systems have been normally introduced to work along with security filmed glass or laminated glass in order to provide more robust blast resistant window systems. The catch systems generally include catch bars and blast curtain, which are installed behind glass panes. The catch system will restrain the excessive deformation of the glass pane or stop the ejecting glass pane from flying towards the occupied area. A few catch systems have been proven effective against higher blast pressures because they enable pressure venting after glass detached from window frame. Some blast curtain or catch membrane can also be used with monolithic glass windows. A 
general problem with catch system is the proper anchorage and installation into the wall because very large constraining force will be required for these catching members.
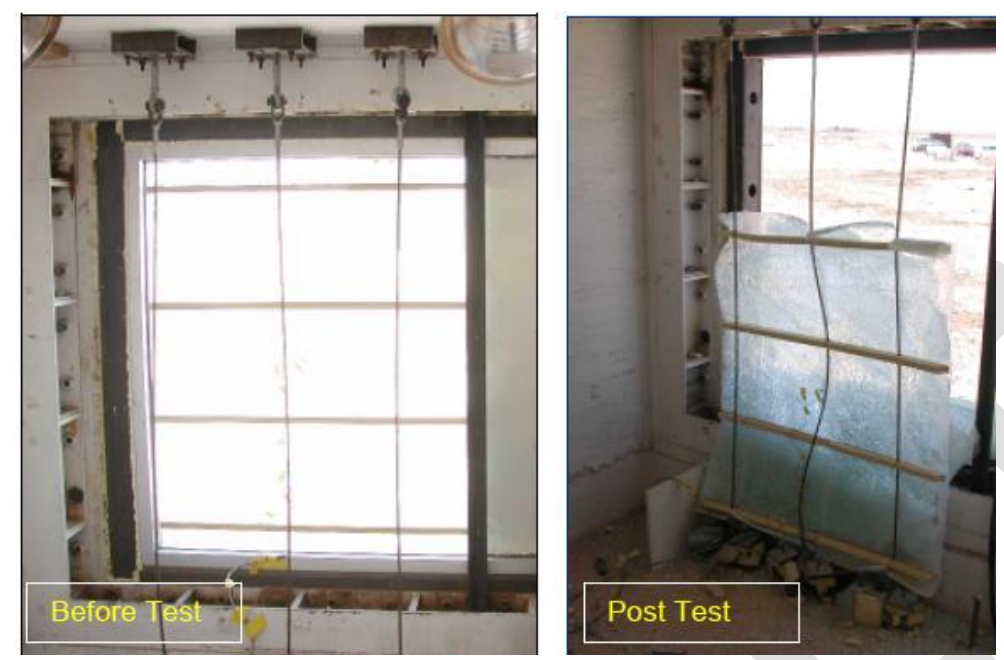

a) Catcher cable system [101]

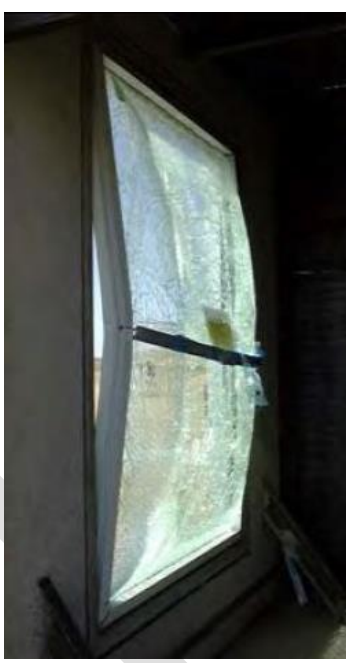

c) Catch bar [100]

\subsection{Interlayer achor}

Figure 22 Catch systems for filmed glass or laminated glass windows

Mitigating the pull-out failure on laminated pane, interlayer anchorage measures such as fixture bars and fixture bolts were introduced to anchor the extended PVB strips to the window frames [100]. Field blast test were carried out to examine the performance of these anchorage measures. The effectiveness of these interlayer anchorage measure under different blast scenarios were evaluated and compared with field blast test results (Figure 23) [98]. The studies found that if properly designed, interlayer anchors will greatly reduce the vulnerability of laminated glass windows with pull-out failure. But under large-scale blast load, interlayer rupture or tearing from the fixture bolts and fixture bars might still occur. The applicability of interlayer anchor is therefore also limited to small and medium level blast scenarios. 

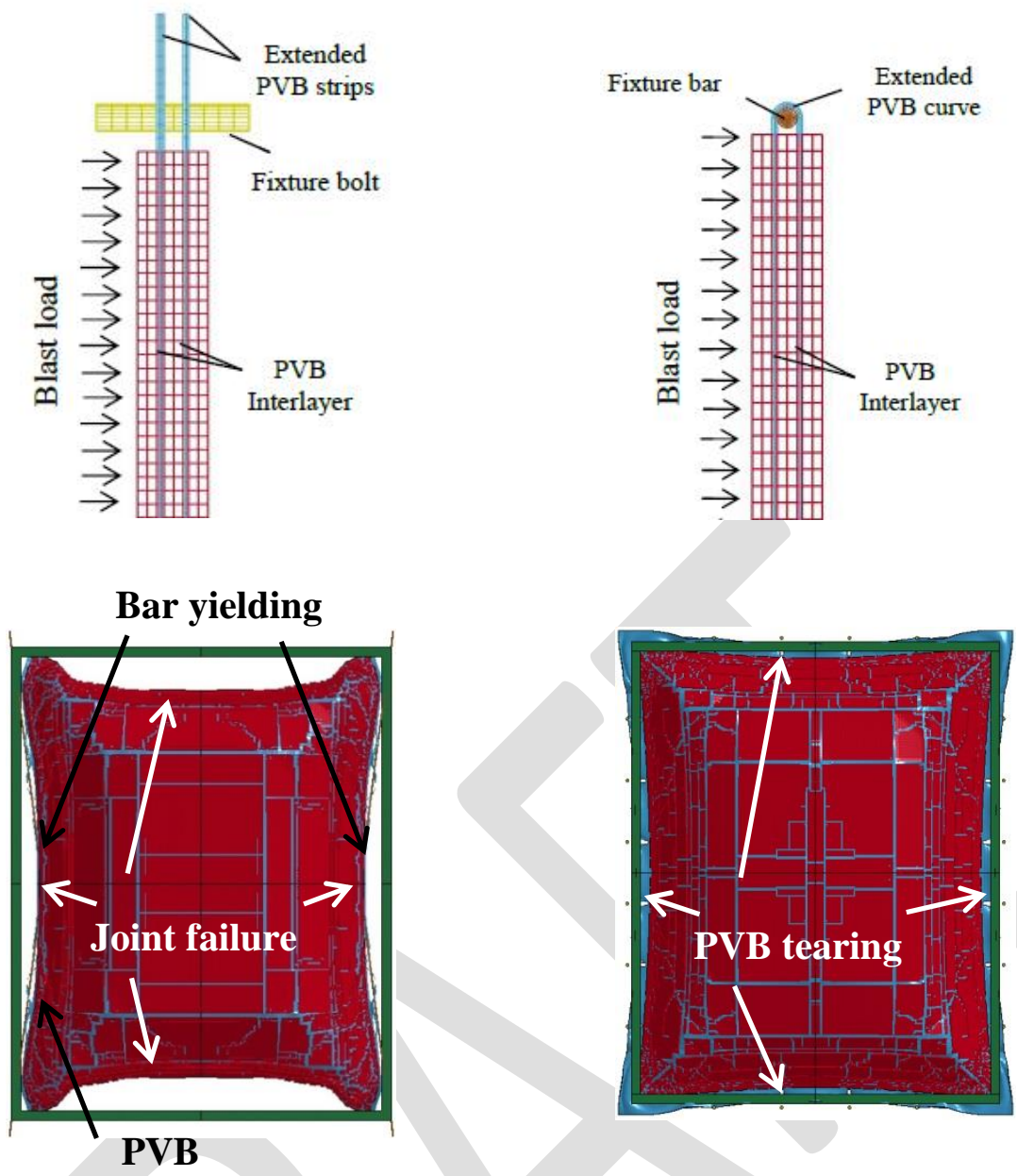

a) Anchorage bars

b) Anchorage bolts

Figure 23 The effectiveness of interlayer anchorage systems under blast load from $90 \mathrm{~kg}$ TNT detonated at $10 \mathrm{~m}$ stand-off distance [98]

5.4 Other strengthening measures

Some new mitigation retrofits and concepts have been introduced in recent years.

For instance, Trawinski et al. [100] developed a damping chamber window frame system (Figure 24). The system includes two glass units separated by a damping chamber. The imposed energy will be consumed by the vibration of the two glass units. If the outer glass unit breaks by air blast wave, pressure will vent through the chamber, thus mitigate the loading on the inner glass pane. 

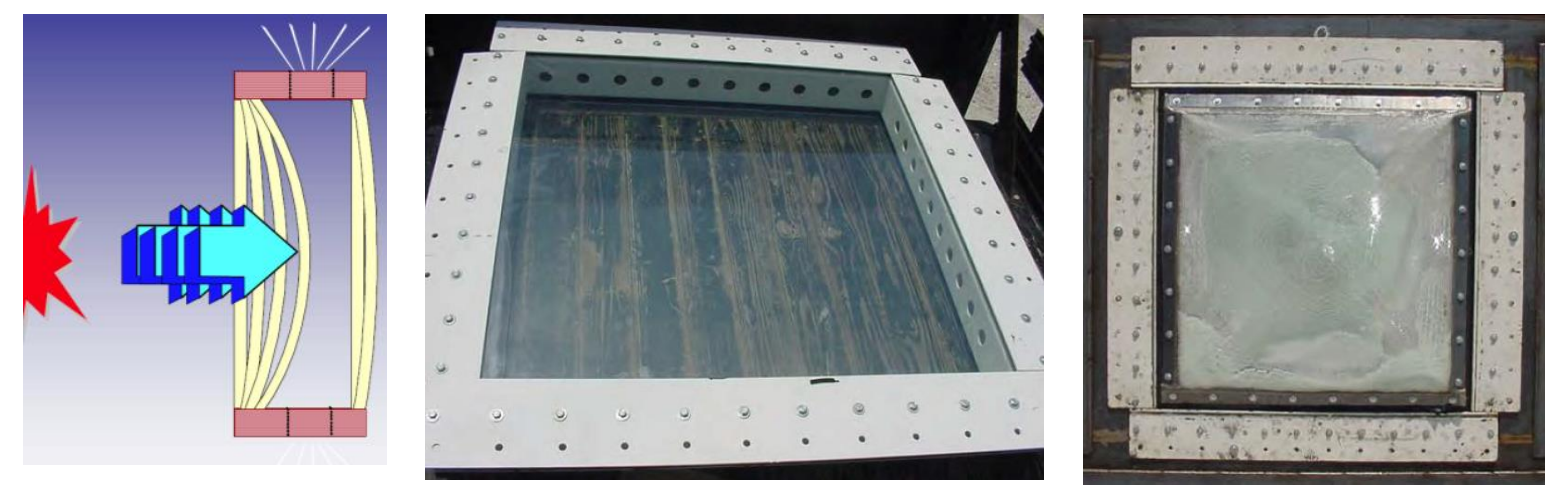

Figure 24 Damping Chamber window frame system [100]

Based on parametric study it was found that the blast resistant capacity of a laminated pane with a pinned boundary performed better than that with a fully fixed boundary. A more flexible 'sliding boundary' was also proposed by Zhang et al. [98]. The concept is to allow glass pane have certain transitional movement in the direction of blast wave. The movement of the glass pane would absorb blast loading energy and hence mitigate damage. Field validation test proofed the laminated glass pane with a sliding boundary performed better than that with a conventional fully fixed boundary (Figure 25). Similar retrofit concept was reported in UK practise, where a punched window was held by a yielding support [102] (Figure 26).

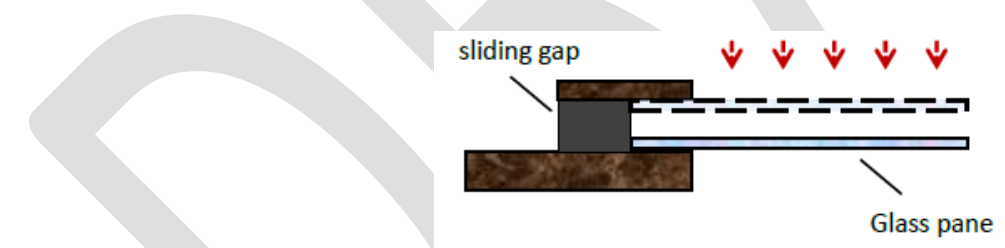

a) Schematic view of sliding boundary system

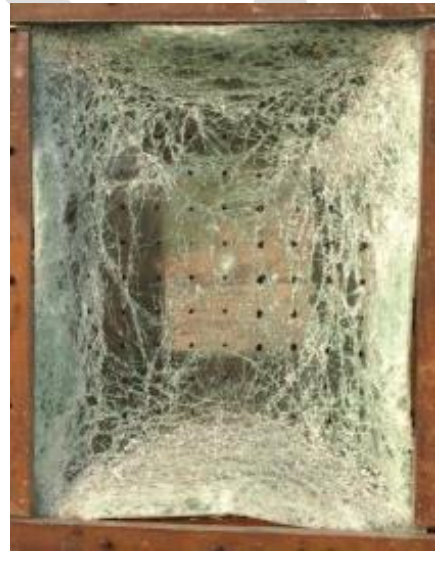

a) Sliding boundary

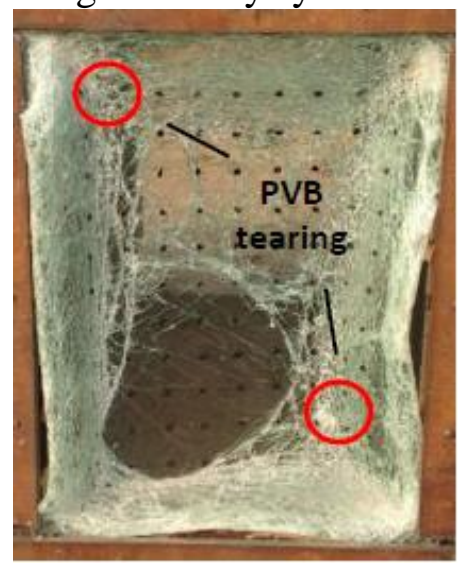

b) Fully fixed boundary

Figure 25 Laminated glass windows with sliding boundary [98] 


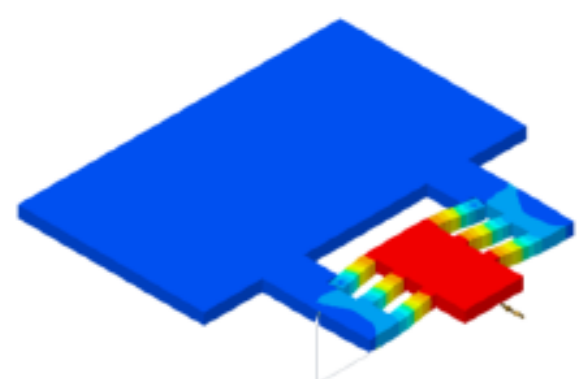

a) Numerical analysis

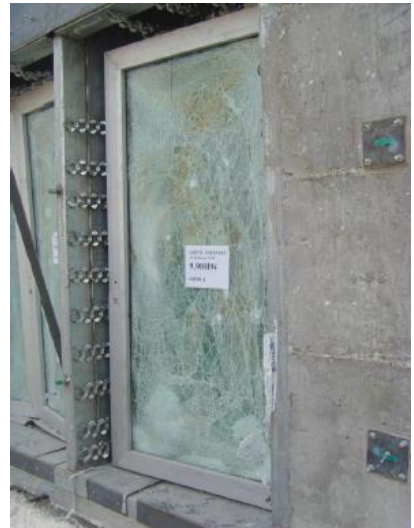

b) Field validation test

Figure 26 Yielding supports for punched windows [102]

Other mitigation measures such as cable supported glazing with energy dissipation connectors [103, 104] are also available in recent years. Their effectiveness was evaluated with numerical studies and/or field tests. However, most of these tests were only case by case. Their effectiveness when applied to windows of other dimensions and blast loads of other scenarios is not fully understood.

\section{Summary}

This paper presents a review of the blast resistant window systems. The history of studies on glass window response to blast loading is briefed. Fundamental knowledge and recent understandings about glass dynamic material properties as well as available material models for annealed glass are summarized. Analysis and design methods for monolithic glass windows are outlined. The characteristics of glass fragments produced by air blast wave are discussed. The up-to-date study about the laminated glass window behaviour under blast loading is reviewed. Recent numerical models and analytical solutions on the response of laminated glass windows are summarized and discussed. Available field blast tests and laboratory tests are also outlined. The accuracies and popularly used design guidelines are assessed. Blast resistant mitigation retrofits are also outlined and their effectiveness discussed.

\section{Acknowledgement}


The authors would like to thank Australian Research Council for financial support to carry out this research.

\section{Reference}

[1] H.S. Norville, N. Harvill, E.J. Conrath, S. Shariat, S. Mallonee, Glass-Related Injuries in Oklahoma City Bombing, Journal of Performance of Constructed Facilities, 13

(1999) 50.

[2] Wikipedia, Norway Attacks, 2011, http://en.wikipedia.org/wiki/2011 Norway attacks.

[3] Glass Research and Testing Laboratory, Misty picture data: Window glass experiment, Texas Technical University, Tex, USA, 1987.

[4] Wikipedia, Laminated glass, https://en.wikipedia.org/wiki/Laminated_glass.

[5] E.B. Philip, Report No. REN 585, Blast and The Ministry of Home Security, Research and Expeirments Department, 1939-1945, Ministry of Home Security, 1945.

[6] D. Pritchard, Breakage of glass windows by explosions, Journal of Occupational Accidents, 3 (1981) 69-85.

[7] D.M. Moore, Proposed method for determining the thickness of glass in solar collector panels, NASA STI/Recon Technical Report N, 80 (1980) 24755.

[8] TM 5-1300, Structures to resist the effects of accidental explosions, Department of the Army, the Navy and the Air Force, Washington DC, USA, 1990.

[9] UFC 3-340-02, Structures to Resist the Effects of Accidental Explosions, Department of Defense, Washington D.C., USA, 2008.

[10] ASTM F2248-09, Standard Practice for Specifying an Equivalent 3-second Duration Design Loading for Blast Resistant Glazing Fabricated with Laminated Glass, West Conshohocken, PA, 2009.

[11] D.G. Christopherson, Paper RC 450, Structural Defence, Ministry of Home Security, London, UK, 1945.

[12] Security Facilities Executive Special Services Group - Explosion Protection, Glazing Hazard Guide, Cabinet Office, London, 1997.

[13] L.A.B. Pilkington, Review lecture. the float glass process, Proceedings of the Royal Society of London. Series A, Mathematical and Physical Sciences, (1969) 1-25.

[14] M.M. Chaudhri, C. Liangyi, The catastrophic failure of thermally tempered glass caused by small-particle impact, Nature, 320 (1986) 48-50.

[15] J.M. Barsom, Fracture of tempered glass, Journal of the American Ceramic Society, 51 (1968) 75-78.

[16] E.K. Beauchamp, R.V. Matalucci, Dynamics of window glass fracture in explosions, SAND98-0598, Sandia National Laboratories, Albuquerque, NM, (1998).

[17] X. Zhang, H. Hao, Z. Wang, Experimental Investigation on Monolithic Tempered Glass Windows Responses to Blast Loads, International Journal of Protective Structures, 6 (2015) 287-309.

[18] M. Overend, G. Parke, D. Buhagiar, Predicting Failure in Glass-A General Crack Growth Model, Journal of Structural Engineering, 133 (2007) 1146-1155.

[19] A.A. Griffith, The Phenomena of Rupture and Flow in Solids, Philosophical Transactions of the Royal Society of London. Series A, Containing Papers of a Mathematical or Physical Character, 221 (1921) 163-198. 
[20] M.G. Stewart, M.D. Netherton, Security risks and probabilistic risk assessment of glazing subject to explosive blast loading, Reliability Engineering \& System Safety, 93 (2008) 627-638.

[21] W.L. Beason, Breakage characteristics of window glass subjected to small missile impacts, Civil Engineering Department, Texas Tech University, 1974.

[22] W.L. Beason, J.R. Morgan, Glass Failure Prediction Model, Journal of Structural Engineering, 110 (1984) 197-212.

[23] prEn 13474-3, Glass in Buildings - Determination of the Strength of Glass Panes. Part 3: General Method of Calculation and Determination of Strength of Glass by Testing, British Standards Institute. London.

[24] X. Zhang, Y. Zou, H. Hao, X. Li, G. Ma, K. Liu, Laboratory Test on Dynamic Material Properties of Annealed Float Glass, International Journal of Protective Structures, 3 (2012) 407-430.

[25] C. Morison, Briefing: The response of glazing to blast loading, Proceedings of the ICE-Engineering and Computational Mechanics, 166 (2013) 128-131.

[26] N. Bourne, J. Millett, Z. Rosenberg, N. Murray, On the shock induced failure of brittle solids, Journal of the Mechanics and Physics of Solids, 46 (1998) 1887-1908.

[27] C. Alexander, L. Chhabildas, W. Reinhart, D. Templeton, Changes to the shock response of fused quartz due to glass modification, International Journal of Impact Engineering, 35 (2008) 1376-1385.

[28] M. Grujicic, W. Bell, B. Pandurangan, B. Cheeseman, C. Fountzoulas, P. Patel, D. Templeton, K. Bishnoi, The effect of high-pressure densification on ballisticpenetration resistance of a soda-lime glass, Proceedings of the Institution of Mechanical Engineers, Part L: Journal of Materials Design and Applications, 225 (2011) 298-315.

[29] W. Brown, A practicable formulation for the strength of glass and its special application to large plates, Tech. Rep. Publication No. NRC14372, National Research Council of Canada, Ottawa, 1974.

[30] T.J. Holmquist, G.R. Johnson, C. Lopatin, D. Grady, E.S. Hertel Jr, High strain rate properties and constitutive modeling of glass, in: Proceedings of 15th International Symposium on Ballistics Jerusalem, Israel, 1995.

[31] M. Peroni, G. Solomos, V. Pizzinato, M. Larcher, Experimental Investigation of High Strain-Rate Behaviour of Glass, Applied Mechanics and Materials, 82 (2011) 6368.

[32] BS EN 572-1, Glass in building. Basic soda lime silicate glass products. Definitions and general physical and mechanical properties., London, UK, 2004.

[33] X. Nie, W.W. Chen, D.W. Templeton, Dynamic Ring-on-Ring Equibiaxial Flexural Strength of Borosilicate Glass, International Journal of Applied Ceramic Technology, 7 (2010) 616-624.

[34] ASTM E1300-09, Standard practice for determining the load resistance of glass in buildings, West Conshohocken, PA, USA, 2009.

[35] D.Z. Yankelevsky, Strength prediction of annealed glass plates-A new model, Engineering Structures, 79 (2014) 244-255.

[36] I. Nurhuda, N.T.K. Lam, E.F. Gad, I. Calderone, Estimation of strengths in large annealed glass panels, International Journal of Solids and Structures, 47 (2010) 25912599. 
[37] prEN 13474-1-1999, Glass in building - design of glass panes. Part 1: General basis of design, European Standards, 1999.

[38] M. Larcher, G. Solomos, F. Casadei, N. Gebbeken, Experimental and numerical investigations of laminated glass subjected to blast loading, International Journal of Impact Engineering, 39 (2012) 42-50.

[39] J. Wei, L.R. Dharani, Response of laminated architectural glazing subjected to blast loading, International Journal of Impact Engineering, 32 (2006) 2032-2047.

[40] J. Wei, M.S. Shetty, L.R. Dharani, Stress characteristics of a laminated architectural glazing subjected to blast loading, Computers \& Structures, 84 (2006) 699-707.

[41] J. Wei, M.S. Shetty, L.R. Dharani, Failure analysis of architectural glazing subjected to blast loading, Engineering Failure Analysis, 13 (2006) 1029-1043.

[42] M. Grujicic, W. Bell, B. Pandurangan, B. Cheeseman, C. Fountzoulas, P. Patel, Molecular-Level Simulations of Shock Generation and Propagation in Soda-Lime Glass, Journal of Materials Engineering and Performance, 21 (2012) 1580-1590.

[43] G. Camacho, M. Ortiz, Computational modelling of impact damage in brittle materials, International Journal of Solids and Structures, 33 (1996) 2899-2938.

[44] M. Grujicic, B. Pandurangan, W.C. Bell, N. Coutris, B.A. Cheeseman, C. Fountzoulas, P. Patel, D.W. Templeton, K.D. Bishnoi, An Improved Mechanical Material Model for Ballistic Soda-Lime Glass, Journal of Materials Engineering and Performance, 18 (2009) 1012-1028.

[45] G.R. Johnson, T.J. Holmquist, An improved computational constitutive model for brittle materials, in: Proceedings of High-pressure science and technology-1993, 1994.

[46] X. Nie, W.W. Chen, A.A. Wereszczak, D.W. Templeton, Effect of Loading Rate and Surface Conditions on the Flexural Strength of Borosilicate Glass, Journal of the American Ceramic Society, 92 (2009) 1287-1295.

[47] X. Zhang, H. Hao, G. Ma, Dynamic material model of annealed soda-lime glass, International Journal of Impact Engineering, 77 (2015) 108-119.

[48] D. Dandekar, P. Beaulieu, Failure wave under shock wave compression in soda lime glass, Metallurgical and Material Applications of Shock-Wave and High-StrainRate Phenomena, (1995) 211-218.

[49] D.E. Grady, L.C. Chhabildas, Shock-wave properties of soda-Lime glass, Sandia National Labs., Albuquerque, , NM, United States (1996).

[50] G.E. Meyers, Design Criteria and Preliminary Acceptance Test, DTIC documents available online, (1984) 153.

[51] J.H. Iverson, Summary of Existing Structures Evaluation Part II: Window Glass and Applications, Office of Civil Defense; Office of the Secretary of the Army, (1968).

[52] S. Timoshenko, S. Woinowsky-Krieger, S. Woinowsky, Theory of plates and shells, McGraw-Hill New York, 1959.

[53] D. Moore, Analytical Modeling of Glass Fracture, Proceedings of the Flat-Plate Solar Array Project Research Forum on Quantifying Degradation JPL Publication Williamsburg, Virginia, 1982, pp. 155-170.

[54] C. Morison, The resistance of laminated glass to blast pressure loading and the coefficients for single degree of freedom analysis of laminated glass, PhD thesis, Cranfield University (2010). 
[55] J. Ge, G.-Q. Li, S.-W. Chen, Theoretical and experimental investigation on fragment behavior of architectural glass panel under blast loading, Engineering Failure Analysis, 26 (2012) 293-303.

[56] Road Research Laboratory, note ARP/61/ARC, paper RC 120, High speed cine photographs of windows subjected to blast from an explosion, Ministry of Home Security, 1941.

[57] G.E. Meyers, D. Baldwin, P. Mlakar, State of the Art of Blast Resistant Windows, DTIC Document, available online (1994).

[58] S. Weissman, N. Dobbs, W. Stea, P. Price, Blast Capacity Evaluation of Glass Windows and Aluminum Window Frames, DTIC Document, available online (1978).

[59] General Services Administration, Standard Test Method for Glazing and Window Systems Subject to Dynamic Overpressure Loadings, US, 2003.

[60] S. Meyer, L. Little, E. Conrath, Injury Based Glass Hazard Assessment, DTIC Document, 2004.

[61] ASTM F1642:2004, Standard Test Method for Glazing and Glazing Systems subject to Air Blast Loadings, West Conshohocken, PA, 2004.

[62] ISO 16933:2007, Explosion-Resistant Security Glazing - Test and Classification for Arena Air-Blast Loading, International Organization for Standardization, 2007.

[63] A.v. Doormaal, J. Weerheijm, M. Rhijnsburger, Hazard of glazing due to blast loading, in: Proceedings of In CD-Rom, Proceedings of the International Symposium on Interaction of the Effects of Munitions with Structures, Florida, USA, 2009.

[64] Y.-Q. Zhang, Y. Lu, H. Hao, Analysis of fragment size and ejection velocity at high strain rate, International journal of mechanical sciences, 46 (2004) 27-34.

[65] X. Zhang, H. Hao, G. Ma, Parametric study of laminated glass window response to blast loads, Engineering Structures, 56 (2013) 1707-1717.

[66] X. Zhang, H. Hao, G. Ma, Laboratory test and numerical simulation of laminated glass window vulnerability to debris impact, International Journal of Impact Engineering, 55 (2013) 49-62.

[67] X. Zhang, H. Hao, G. Ma, Development of PI curve for laminate glass windows, in: Proceedings of Australasian Structural Engineering Conference 2012: The past, present and future of Structural Engineering, 2012.

[68] X. Zhang, H. Hao, Laboratory Test and Numerical Simulation of Laminated Glass Window Response to Impact and Blast Loads, in: Proceedings of the 9th International Conference on Shock \& Impact Loads on Structures, Fukuoka, Japan, 2011.

[69] J. Locke, J.A. Unikowski, Breaking of flat glass-part 1: size and distribution of particles from plain glass windows, Forensic science international, 51 (1991) 251262.

[70] E.R. Fletcher, D.R. Richmond, J.T. Yelverton, Glass fragment hazard from windows broken by airblast, DTIC Document, (1980).

[71] X. Zhang, H. Hao, Z. Wang, Experimental investigation of monolithic tempered glass fragment characteristics subjected to blast loads, Engineering Structures, 75 (2014) 259-275.

[72] D. Bogosian, H.D. Avanessian, To Film Or Not To Film: Effects Of Anti-Shatter Film On Blunt Trauma Lethality From Tempered Glass, DTIC Document, 2002. 
[73] N. Gebbeken, T. Bermbach, Protective Glazing - A Challenge to Numerical Simulation, in: Proceedings of 6th International Conference on Protection of Structures against Hazards, Tianjin, China, 2014.

[74] A.V. Duser, A. Jagota, S.J. Bennison, Analysis of glass/polyvinyl butyral laminates subjected to uniform pressure, Journal of engineering mechanics, 125 (1999) 435442.

[75] S.J. Bennison, A. Jagota, C.A. Smith, Fracture of glass/poly (vinyl butyral)(Butacite ${ }^{\circledR}$ ) laminates in biaxial flexure, Journal of the American Ceramic Society, 82 (1999) 1761-1770.

[76] P. Hooper, B. Blackman, J. Dear, The mechanical behaviour of poly (vinyl butyral) at different strain magnitudes and strain rates, Journal of Materials Science, 47 (2012) 3564-3576.

[77] X. Zhang, H. Hao, Y. Shi, J. Cui, The Mechanical Properties of Polyvinyl Butyral (PVB) for Laminated Glass at High Strain Rates, Construction and Building Materials, (2015).

[78] R. Iwasaki, C. Sato, J. Latailladeand, P. Viot, Experimental study on the interface fracture toughness of PVB (polyvinyl butyral)/glass at high strain rates, International Journal of Crashworthiness, 12 (2007) 293-298.

[79] B. Liu, Y. Sun, Y. Li, Y. Wang, D. Ge, J. Xu, Systematic experimental study on mechanical behavior of PVB (polyvinyl butyral) material under various loading conditions, Polymer Engineering \& Science, 52 (2012) 1137-1147.

[80] S. Bennison, J. Sloan, D. Kistunas, P. Buehler, T. Amos, C. Smith, Laminated glass for blast mitigation: Role of interlayer properties, in: Proceedings of Glass Processing Days, Tampere, Finland, 2005.

[81] J. Belis, J. Depauw, D. Callewaert, D. Delincé, R. Van Impe, Failure mechanisms and residual capacity of annealed glass/SGP laminated beams at room temperature, Engineering Failure Analysis, 16 (2009) 1866-1875.

[82] X. Zhang, Y. Shi, H. Hao, J. Cui, The Mechanical Properties of lonoplast Interlayer Material at High Strain Rates, Manuscript under review with Materials \& Design, (2015).

[83] C. Morison, M. Zobec, A. Frenceschet, The measurement of PVB properties at high strain rates, and their application in the design of laminated glass under bomb blast, in: Proceedings of Proceedings of the International Symposium on Interaction of the Effect of Munitions with Structures, Florida, USA, 2007.

[84] P.A. Hooper, R.A.M. Sukhram, B.R.K. Blackman, J.P. Dear, On the blast resistance of laminated glass, International Journal of Solids and Structures, 49 (2012) 899-918.

[85] M. Nawar, H. Salim, B. Lusk, S. Kiger, Modeling and Shock Tube Testing of Architectural Glazing Systems for Blast Resistance, Journal of Structural Engineering, (2014) 04014174.

[86] J. Oda, M. Zang, Analysis of impact fracture behavior of laminated glass of bilayer type using discrete element method, Key Engineering Materials, 145 (1997) 349-354.

[87] M. Zang, Z. Lei, S. Wang, Investigation of impact fracture behavior of automobile laminated glass by 3D discrete element method, Computational Mechanics, 41 (2007) 73-83. 
[88] M.Y. Zang, H. Chen, Z. Lei, Simulation on High Velocity Impact Process of Windshield by SPH/FEM Coupling Method, 2010 WASE International Conference on Information Engineering (ICIE), 2010, pp. 381-384.

[89] D. Cormie, Mays, G., Smith, P., Blast Effects on Buildings, Thomas Telford Publications, Heron Quay, London, 2009.

[90] M. Teich, N. Gebbeken, The Influence of the Underpressure Phase on the Dynamic Response of Structures Subjected to Blast Loads, International Journal of Protective Structures, 1 (2010) 219-234.

[91] T. Krauthammer, A. Altenberg, Negative phase blast effects on glass panels, International Journal of Impact Engineering, 24 (2000) 1-17.

[92] B.R. Ellis, Report TCR 28/91, Static testing of glazing for property service agency, Building Research Establishment, 1991.

[93] X. Zhang, H. Hao, Z. Wang, Experimental study of laminated glass window responses under impulsive and blast loading, International Journal of Impact Engineering, 78 (2015) 1-19.

[94] J.M. Biggs, Introduction to structural dynamics, New York, 1964.

[95] UFC 4-010-01, Minimum Anti-Terrorism Standards for Buildings, Department of Defense, Washington D.C., USA, 2003.

[96] C. Kranzer, G. Gürke, C. Mayrhofer, Testing of Bomb Resistant Glazing SystemsExperimental Investigation of the Time Dependent Deflection of Blast Loaded 7.5 $\mathrm{mm}$ Laminated Glass, in: Proceedings of Proceedings of Glass Processing Days, Tampere, Finland, 2005.

[97] W.C. Wedding, B.T. Lusk, Novel method to determine blast resistant glazing system response to explosive loading, Measurement, 45 (2012) 1471-1479.

[98] X. Zhang, H. Hao, Experimental and numerical study of boundary and anchorage effect on laminated glass windows under blast loading, Engineering Structures, 90 (2015) 96-116.

[99] L.H. Lin, E. Hinman, H.F. Stone, A.M. Roberts, Survey of Window Retrofit Solutions for Blast Mitigation, Journal of Performance of Constructed Facilities, 18 (2004) 86-94.

[100] Elizabeth Trawinski, Jeff W. Fisher, R.J. Dinan, Full Scale Testing of Polymer Reinforced Blasting Resistant Windows, Air Force Research Laboratory, Florida, USA, 2004.

[101] L. Shengrui, C.J. E., Numerical Simulation on Blast Response of a Cable Catcher System for Glazing Facade, 10th International Conference on Shock \& Impact Loads on Structures, Singapore, 2013.

[102] M. Colin, Analysis of glazing under blast loading, Urban habitat constructions under catastrophic events Naples, 2010.

[103] C. Amadio, C. Bedon, Viscoelastic spider connectors for the mitigation of cablesupported façades subjected to air blast loading, Engineering Structures, 42 (2012) 190-200.

[104] C. Amadio, C. Bedon, Elastoplastic dissipative devices for the mitigation of blast resisting cable-supported glazing façades, Engineering Structures, 39 (2012) 103-115. 